Review

\title{
Research frontiers in penaeid shrimp reproduction: Future trends to improve commercial production
}

\author{
Jorge Alfaro-Montoya $^{\mathrm{a}, *}$, André Braga ${ }^{\mathrm{b}}$, Rodolfo Umaña-Castro \\ ${ }^{a}$ Laboratorio de Cultivo y Fisiología Reproductiva de Crustáceos, Escuela de Ciencias Biológicas, Universidad Nacional, Heredia, Costa Rica \\ ${ }^{\mathrm{b}}$ Instituto de Investigaciones Oceanológicas, Universidad Autónoma de Baja California, Ensenada, Mexico \\ ${ }^{\mathrm{c}}$ Laboratorio de Análisis Genómico, Escuela de Ciencias Biológicas, Universidad Nacional, Heredia, Costa Rica
}

\section{A R T I C L E I N F O}

\section{Keywords:}

Shrimp biotechnology

Controlled reproduction

Penaeids

Litopenaeus vannamei

Penaeus monodon

\begin{abstract}
A B S T R A C T
Shrimp farming worldwide is based on a similar technological package, characterized by three phases: Controlled Reproduction, Larvae Culture, and Grow-out Culture. This basic aquaculture package uses broodstock animals, with different levels of fundamental genetic selection, induced to mature and reproduce based on unilateral eyestalk ablation. This review identified ten reproduction-related research subjects that can improve the shrimp industry based on basic scientific knowledge and four levels of application: eyestalk ablation alternatives, larvae production, product protection, and grow-out yield improvement. Species-specificity must be considered in developing biotechnology solutions. Alternatives to eyestalk ablation for controlling ovarian maturation are based on neurotransmitter regulation in Litopenaeus; however, the environmental impact of this approach has to be evaluated. Maturation by RNAi requires further evaluation, and maturation pheromones have not been explored. Sex reversal, hybridization, in vitro fertilization, and seedstock cryopreservation of penaeids require fundamental research. Triploid culture and genetic selection can be applied to some species for product protection; however, for L. vannamei, triploidization is not practical yet.
\end{abstract}

\section{Introduction}

The worldwide culture of marine shrimps has grown to become one of the most productive aquaculture sectors, representing the second main group of exported species in terms of value. This production is based on an American species, Litopenaeus vannamei and an Asian species, Penaeus monodon. The first one, reaching $86 \%$ of the 4.8 million tonnes world production for 2016 (FAO, 2018).

Importantly, mariculture of $P$. monodons has been heavily impacted by disease outbreaks, slow growth, shrimp prices, and male fertility (Pongtippatee et al., 2007). On the other hand, irrespective of the low biotechnological level of the industry, $P$. vannamei is performing admirably. The latter species has been cultured worldwide, mainly in Latin America, East and Southeast Asia, and India, in marine coastal systems as well as in inland freshwater or saline-alkaline environments (FAO, 2018).

Shrimp farming worldwide is based on a similar technological package, characterized by three phases: Controlled Reproduction, Larvae Culture, and Grow-out Culture. In general, this basic aquaculture package uses broodstock animals, with different levels of fundamental genetic selection, induced to mature and reproduce based on unilateral eyestalk ablation. Nauplii of both sexes are produced and cultured under a standard protocol using live and artificial food, to supply the grow-out industry with young postlarvae that are grown to market sizes under different density models from extensive to hyper intensive conditions (FAO, 2004; Biao and Kaijin, 2007; Valverde-Moya and Alfaro-Montoya, 2014; Xu et al., 2018).

Advances in different research areas, including engineering, water management, nutrition, immunology, pathology, genetics and reproduction, will contribute to improving the culture technology. This review identifies major research subjects that are fundamental for the culture of penaeid shrimps specially focusing in the controlled reproduction of 'superior' animals that offer productive advantages to the present status of the industry.

Fig. 1 summarizes these research subjects covered in the review. Ten reproduction-related research subjects that have the potential for improving the shrimp industry are defined based on basic scientific knowledge and four levels of application: eyestalk ablation alternatives, product protection, grow-out yield improvement, and larvae production. The status of each subject is reviewed and future research trends for its improvement are discussed.

\footnotetext{
* Corresponding author.

E-mail address: jorge.alfaro.montoya@una.cr (J. Alfaro-Montoya).
} 


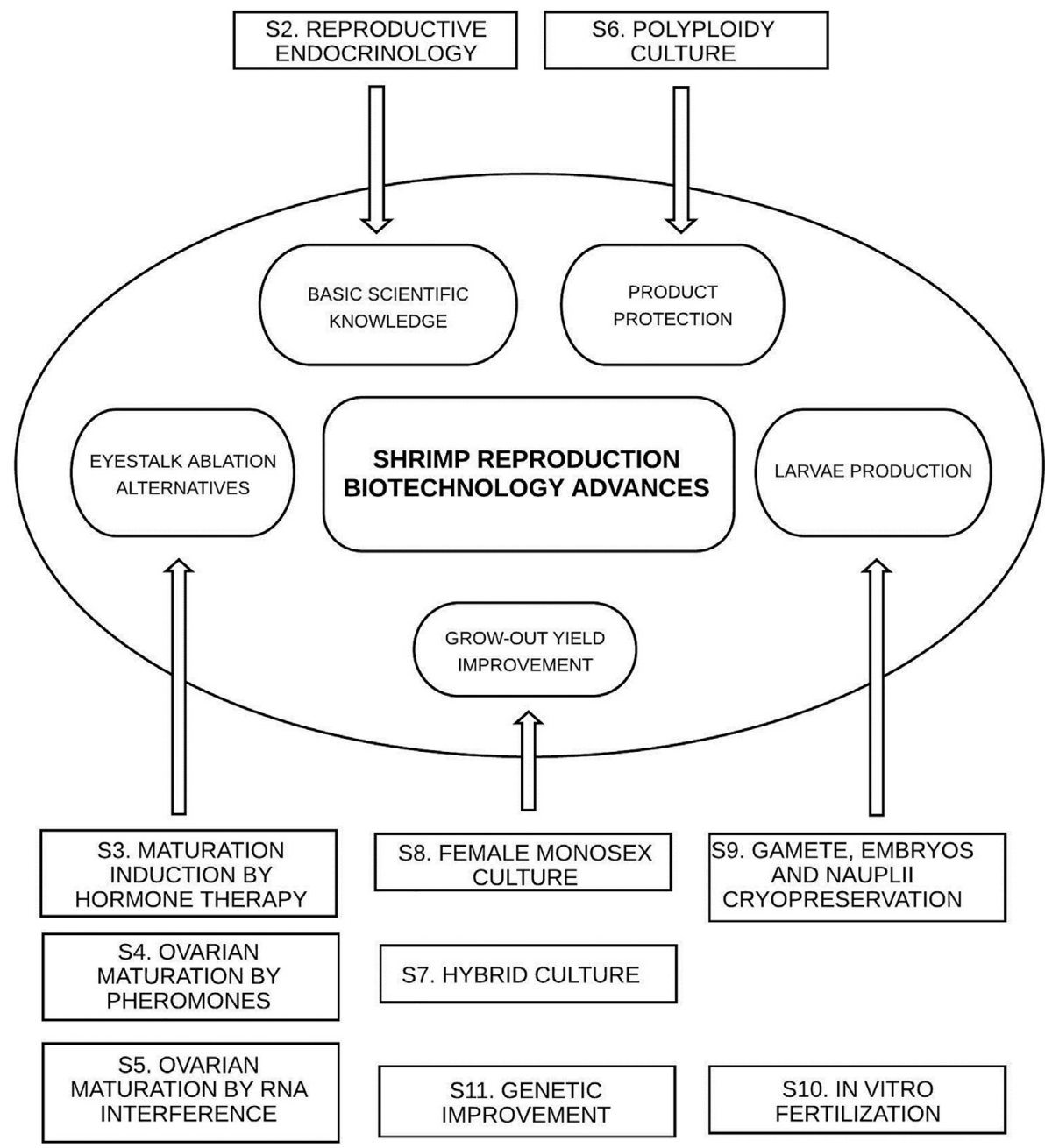

Fig. 1. Schematic representation of the ten reproduction-related research subjects identified as potential improving fields for the shrimp industry. $\mathrm{S}=$ section number.

\section{Reproductive endocrinology}

The basic model for the physiological regulation of shrimp reproduction establishes a cascade and antagonistic hormonal control, based on three levels: (i) central nervous system (CNS)/ x-organ-sinus gland level, (ii) androgenic gland (AG, males)/mandibular organ (MO), and (iii) male/female reproductive system and complementary target tissues (hepatopancreas, appendages) (Okumura, 2004; Nagaraju, 2011). At the highest regulatory level, the endocrine cascade involves biogenic amines, including serotonin that activates vitellogenesis and indirectly affects meiotic maturation (Tomy et al., 2016). This pathway is followed by neuropeptides from the central nervous system; the most known neurohormone belongs to the crustacean hyperglycemic hormone $(\mathrm{CHH})$ family: the vitellogenesis inhibiting hormone (VIH) or gonad inhibiting hormone (GIH) from the x-organ-sinus gland, negatively regulating oocyte maturation and spermatogenesis. In L. vannamei, GIH is predominantly expressed in the brain, and unilateral eyestalk ablation reduces its expression (Chen et al., 2014).

The brain and the thoracic ganglia could release an antagonistic hormone: gonad stimulating hormone (GSH), which activates the reproductive systems and accessory target tissues (Fingerman, 1997). The molecular structure of the presumptive GSH has not been determined; however, it was proposed that a gonadotropin-releasing hormone (GnRH) produced in the CNS activates the release of a gonadotropin hormone (GH) or GSH (Diwan, 2005). Recently, Rotllant et al. (2018) proposed that the difficulty encountered in the isolation of a gonad stimulating factor (GSF) could be related with the existence of different factors among crustaceans for stimulating vitellogenesis or that a GSF is not needed based on a negatively controlled mechanism from the $\mathrm{x}$ organ-sinus gland level.

GnRH-like molecules are decapeptides identified using interspecific antibodies in the CNS and ovaries of various decapod crustaceans, including three species of Penaeidae: Penaeus monodon (Ngernsoungnern et al., 2008), Marsupenaeus japonicus (Amano et al., 2009), and Litopenaeus vannamei (Tinikul et al., 2011). Recently, GnRH has also been detected in the CNS and testis of the crab Portunus pelagicus (Senarai et al., 2016). Tinikul et al. (2011) proposed that serotonin stimulates the release of GnRHs from the brain, the subesophageal ganglion, and the thoracic ganglia, and complementarily inhibits the release of GIH from eyestalks. Dopamine induces the opposite effects on reproduction.

The reproductive role of GnRHs in vertebrates is well established (Tinikul et al., 2014); however, in crustaceans, GnRH has been identified only from Procambarus clarkii (Guan et al., 2014) and Macrobrachium rosenbergii (Suwansa-ard et al., 2016); their sequences are different from previous vertebrate and invertebrate GnRHs and the mechanism of action is still unknown. Ngernsoungnern et al. (2009) proposed that GnRH might regulate ovarian maturation by activating the release of the presumptive GSH.

The current knowledge on GnRH function in relation to reproduction is contradictory since Suwansa-ard et al. (2016) found no effect of $M$. rosenbergii $\mathrm{GnRH}$ on germ cell proliferation, ovarian maturation and lipid metabolism. However, Tinikul et al. (2014), injecting GnRHs from 


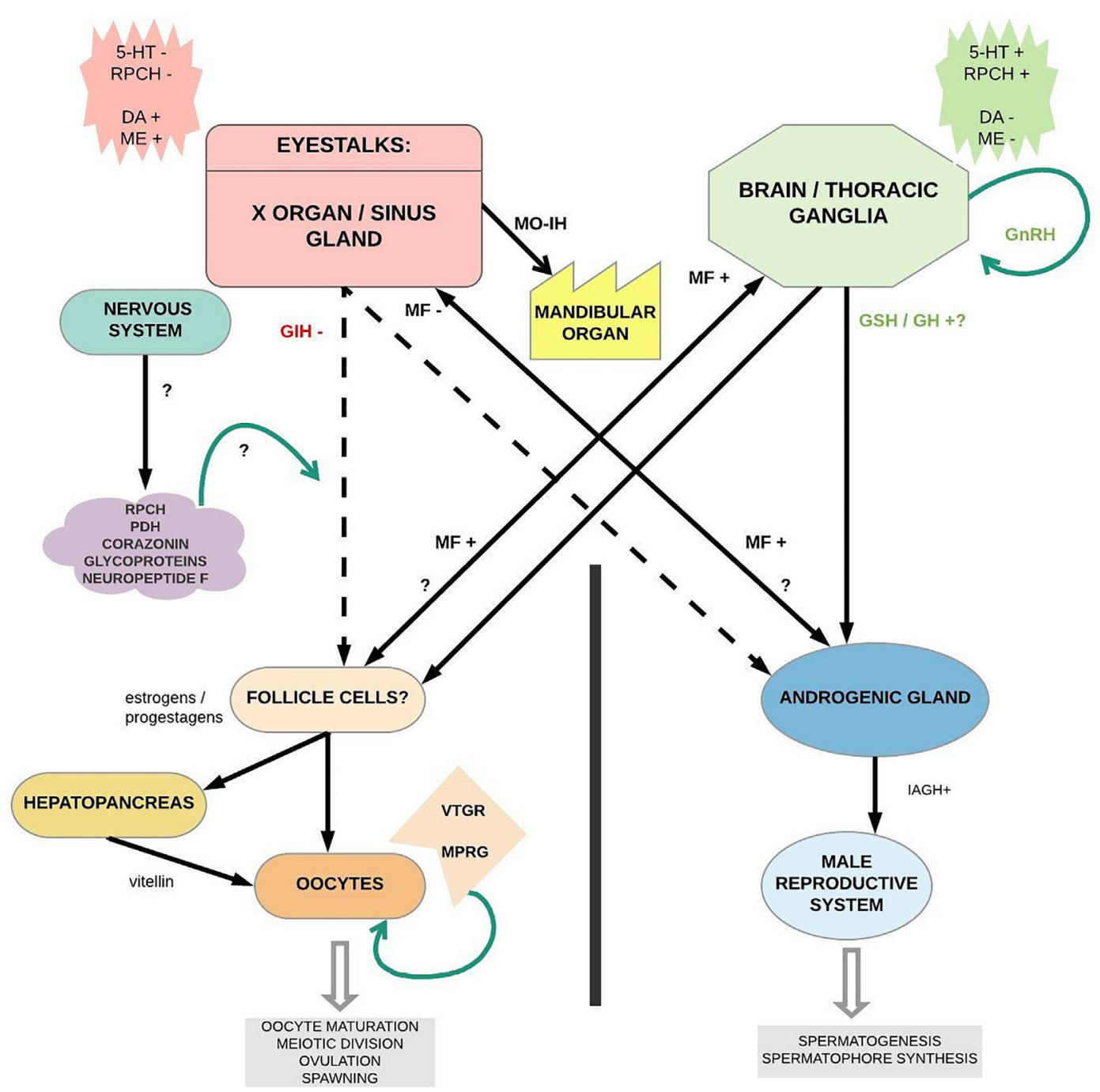

Fig. 2. Current knowledge of the endocrine control of penaeid reproduction. The acronyms are defined in Section 2 of this Review.

octopus and lamprey into L. vannamei, induced a sooner activation of ovarian maturation and an increased gonadosomatic index, but egg production was similar to the vehicle control group. Apparently, maturation and spawning were spontaneously activated in the control group. Similar reproductive effects were also measured in $M$. rosenbergii, injecting exogenous GnRHs (Ngernsoungnern et al., 2009).

Other factors belonging to the GnRH superfamily of neuropeptides that have been associated with the control of reproduction in decapod crustaceans include red pigment concentrating hormone (RPCH), pigment-dispersing hormone (PDH), and corazonin (Rotllant et al., 2018). Chen et al. (2018) demonstrated that the injection of synthetic RPCH activates indicators of ovarian maturation such as ovarian vitellogenin mRNA levels, and that serotonin stimulates RPCH transcript levels in the ovaries of L. vannamei.

Gonadotropins have been suggested to be involved in crustacean reproduction since follicular-stimulating hormone (FSH) and luteinizing hormone (LH) have been identified in decapod crustaceans, including $M$. japonicus. These hormones belong to the glycoprotein hormone family, and a new hormone recently discovered: glycoprotein GPB5 or thyrostimulin, has been demonstrated in some crustaceans, and its role in reproduction has to be elucidated (Rotllant et al., 2018, for review). A complementary family of neuropeptides: neuropeptide F has been identified in crustaceans, including some penaeid shrimps, and it was associated with ovarian maturation in $M$. rosenbergii (Tinikul et al., 2017).
An intermediate level of endocrine control is activated by the CNS: the mandibular organ (MO). This epithelial gland produces the sesquiterpenoid methyl farnesoate (MF) implicated in the regulation of reproduction in different crustaceans. However, its role in reproduction cannot be considered as universal among crustaceans (Nagaraju, 2007). MF seems to have a direct stimulatory effect on ovarian and testicular development, based on the presence of MF receptors in these organs (Nagaraju, 2007, for review). Concerning penaeid shrimps, induction of ovarian maturation by MF has only been reported for Fenneropenaeus indicus (Nagaraju et al., 2002). Alfaro et al. (2008a, 2008b) reported a significant improvement in sperm counts and sperm abnormalities in L. vannamei using MF. The synthesis of MF is inhibited by serotonin; therefore, this neurotransmitter was proposed as a neuroregulator of MF synthesis (Homola et al., 1989; Fingerman, 1997, for review). In L. vannamei, the key enzyme for MF synthesis: farnesoic acid $O$-methyl transferase was expressed in different tissues, and the highest expression was measured in the brain (Ventura-López et al., 2017).

The CNS activates a lower level of the hormonal cascade to release steroid hormones, which regulates the process of ovarian maturation and meiotic division. The role of steroid hormones in crustaceans may be similar to fish and amphibia, where estrogens stimulate vitellogenesis and progestagens induce oocyte maturation (Fairs et al., 1990). In the lobster, Homarus americanus, steroidogenesis is associated with the follicle cells (Talbot, 1981).

Merlin et al. (2016) suggested that the hepatopancreas could be the 
major organ responsible for progesterone and estradiol synthesis in $P$. monodon; progesterone levels seem to increase in hemolymph and ovary for advanced vitellogenic stages. Complementarily, Thongbuakaew et al. (2016) demonstrated the presence of progesterone and estradiol in the CNS, hepatopancreas and ovaries of $M$. rosenbergii; gene expression of key enzymes associated with steroidogenesis was detected in many tissues including the CNS.

In the crab, Oziothelphusa senex senex, Swetha et al. (2016) studied the role of estradiol and progesterone on reproduction; the authors suggested that these sex steroids control ovarian growth and maturation through an ecdysteroid receptor since no other steroid receptor has been discovered in crustaceans.

Prostaglandins are lipids derived from arachidonic acid and have been associated with ovarian maturation in penaeid shrimps. Following different experimental approaches in $M$. japonicus, $P$. monodon, and $\mathrm{L}$. vannamei, prostaglandin concentration seems to decrease during ovarian development. However, some findings have been contradictory, novel PGs have to be identified, and the effect may be dependent on the molecule and the species (Alfaro-Montoya, 2015; Rotllant et al., 2018).

New candidate genes putatively involved in the control and regulation of gonad maturation have been identified in L. vannamei using a transcriptomic approach (Ventura-López et al., 2017), and in $P$. monodon using oligonucleotide microarray analysis (Brady et al., 2013). In L. vannamei, the authors reported a vitellogenin receptor gene (VTGR) with the highest expression in previtellogenic gonads. The brain showed high expression profiles of genes such as farnesoic acid $O$ methyl transferase (FAMET) and insulin-like growth factor binding protein (IGFBP), suggesting an interaction between the insulin/insulinlike growth factor signaling pathway (IIS) and MF biosynthesis. A vertebrate type steroid receptor: membrane progestin receptor gamma (MPRG) was highly expressed in hepatopancreas and intestine, and adult female gonads, suggesting a role of this receptor in sexual maturation. In $P$. monodon, the vitellogenin gene and the lipid storage droplet gene showed higher expression in wild-caught females at advance stages of oocyte maturation. Fig. 2 summarizes the current knowledge of the endocrine control of penaeid reproduction.

\section{Male and female maturation induction by hormone therapy}

Based on the accumulated knowledge about the endocrinological mechanism for the control of ovarian maturation, different applications have been evaluated for inducing the predictable and reliable production of shrimp eggs as an alternative to unilateral eyestalk ablation.

Molecules such as steroids, juvenoids, prostaglandins, neurotransmitters, and neurotransmitter antagonists have been tested. Steroids and prostaglandins have not given commercially applicable results for female maturation (Yano, 1985, 1987; Tsukimura and Kamemoto, 1991; Alfaro-Montoya, 2015); however, in L. vannamei males, Alfaro (1996) demonstrated a significant improvement in spermatophore quality by injecting 17 alpha-methyltestosterone.

Concerning juvenoids, methyl farnesoate (MF) and juvenile hormone (JH III) stimulated in vitro immature ovaries in L. vannamei (Tsukimura and Kamemoto, 1991), and ovarian maturation was induced in F. indicus (Nagaraju et al., 2002). In L. vannamei males, Alfaro et al. (2008a, 2008b) reported a significant improvement in sperm counts and sperm abnormalities injecting MF.

Neurotransmitters, particularly serotonin has given the most promising results for inducing ovarian maturation. Based on the findings by Sarojini et al. (1995) that established that serotonin induces ovarian maturation in vivo and in vitro, in Pr. clarkii, the molecule was studied as an alternative to eyestalk ablation in various penaeid species. The first study was done for L. vannamei, generating ovarian maturation at rates lower than unilateral eyestalk ablation (Vaca and Alfaro, 2000); then, serotonin was tested in $P$. monodon and $F$. indicus, inducing maturation and spawning at rates similar to eyestalk ablation (Wongprasert et al.,
2006; Santhoshi et al., 2009).

Based on the multifactorial regulation of female shrimp reproduction (Huberman, 2000), a combined molecular therapy has only been applied by Alfaro et al. (2004). The induction of ovarian maturation and spawning in serotonin/spiperone injected females as well as in nontreated females was continuous for 3-4 months in L. vannamei and 6 months in Litopenaeus stylirostris, suggesting that the new experimental protocol is a remarkable alternative for the traditional eyestalk ablation. The production of eggs was predictable generating similar nauplii yields to eyestalk ablation. This study also evaluated the combined injection of serotonin plus JH III without any ovarian induction. Despite these unique findings for a practical alternative to eyestalk ablation, no other scientific study or commercial testing have been reported.

Another hormonal approach follows Otsu (1960) who found that implantation of thoracic ganglia from a mature female into an immature female stimulates vitellogenesis. Yano et al. (1988) evaluated this principle on L. vannamei by implanting thoracic ganglia from maturing H. americanus. However, Hooi (1991) evaluated intraspecific thoracic ganglia extracts from spent spawners in $P$. monodon, without success. Then, Alfaro et al. (2004) demonstrated for the first time that interspecific and intraspecific thoracic ganglia transplants from Penaeidae are gradually absorbed by the host without activating an encapsulation mechanism, compromising any practical application of this technology. Complementarily, Alfaro and Vega (2010) established that thoracic ganglia extracts or implants from maturing penaeid females were not capable of inducing a clear response in sexual maturation in males or females of L. stylirostris, L. vannamei and Rimapenaeus byrdi. Among new hormone candidates for maturation, synthetic RPCH has been suggested as a potential inducer in L. vannamei (Chen et al., 2018).

\section{Ovarian maturation induction by pheromones}

Aquatic organisms like terrestrial animals use olfaction and gustation as chemoreception mechanisms for activating biological processes such as reproduction, social interactions, food acquisition, shelter, and defense (Derby and Sorensen, 2008). Chemical signals in crustaceans have been demonstrated in many groups; however, identification of sex pheromones in decapod crustaceans has been inconclusive or incomplete (Derby and Sorensen, 2008; Okamura et al., 2017)).

Concerning ovarian maturation and spawning inducing pheromones, these molecules have been identified in fish. In the goldfish, Carassius auratus, Scott and Sorensen (1994) demonstrated that ovulatory females release many steroids into the water, and the most active pheromones were the oocyte maturation-inducing steroid: $17 \alpha, 20 \beta$ dihydroxypregn-4-en-3-one $(17,20 \beta-P)$, the $17 \alpha, 20 \beta, 21$-trihydroxypregn-4-en-3-one $(17,20 \beta-21 \mathrm{P})$, and androstenedione. In the Mozambique tilapia (Oreochromis mossambicus), dominant males release two epimeric steroids: $20 \alpha$ - and 20ß- pregnanetriol 3-glucuronates, which induce the release of $17,20 \beta-P$ by females, accelerating ovarian maturation and spawning synchrony (Keller-Costa et al., 2014).

The first crustacean sex pheromone was isolated by Hardege et al. (2011) from the crab, Carcinus maenas. The pheromone is a nucleotide: uridine diphosphate, which is released from urine as a product of chitin biosynthesis, and induces sexual behaviors in males. In Lysmata bogessi, a cuticle-bound contact sex pheromone was isolated (Zhang et al., 2011). This pheromone induces mating behavior and the major component is the cuticular hydrocarbon: (Z)-9-octadecenamide.

Bose et al. (2017) reported an integrated study of the biomolecular activity of $M$. rosenbergii antennal glands (AnG), based on three research axes: transcriptomics, proteomics and metabolomics. Their findings included a crustacyanin-like lipocalin gene that belongs to a family of transport proteins for small hydrophobic biomolecules such as steroids, retinoids, lipids and pheromones. Among the metabolites identified from the AnG, uric acid and $N$-acetylglucosamine-1,5-lactone (NAGL) were proposed as courtship pheromones in the polychaeta, Platynereis 
dumerilii (Zeeck et al., 1998), and in the blue crab, Callinectes sapidus (Kamio et al., 2014), respectively. Other reproduction-related metabolites tentatively identified were juvenile hormone 1 (JH 1) and MF. The most abundant protein in the AnG was haemocyanin subunit 1 , which could be involved in different biological processes other than oxygen transport, including endogenous and exogenous transport of NAGL.

A reliable species-specific bioassay is essential to identify sex pheromones (Okamura et al., 2017). These authors developed a precopulatory guarding bioassay for the hermit crab, Pagurus filholi, for the basic chemical characterization of the pheromone involved. Kamio et al. (2014) followed a bioassay-guided fractionation and a biomarker targeting approach that identified NAGL as one of the pheromone components involved in courtship behavior of $C$. sapidus.

In crustaceans, reproductive pheromones have only been related with mating behavior. In penaeid shrimps, the only report suggesting the existence of ovarian maturation inducing pheromones was provided by Alfaro et al. (2004). The authors discovered that by injecting serotonin plus spiperone into cultured L. vannamei and wild L. stylirostris females, ovarian maturation was activated directly by the combined action of the molecules, but also indirectly in non-treated females. The technique induced ovarian maturation at rates similar to eyestalk ablation in both species; therefore, the authors proposed that maturation promoting pheromones were involved in this process. Eyestalk ablation is still the technique used for inducing ovarian maturation of penaeid shrimps at commercial facilities worldwide, and it seems that under this protocol no maturation pheromones can be activated since unablated control females do not normally produce eggs. Eyestalk ablation has been recognized as a destructive technique, which alters the complete physiology of crustaceans, generating low relative maturation yields (Quackenbush, 1986; Bray et al., 1990a, 1990b; Benzie, 1998).

Further efforts should be made for elucidating the molecular structure and endocrine mechanism of action of this hypothetical pheromone. The direct injection of serotonin/spiperone is an alternative to eyestalk ablation in L. vannamei and L. stylirostris; however, the treatment causes some mortality and requires periodic injection. On the contrary, pheromone therapy is non-invasive, offering the industry a unique approach to controlled reproduction.

\section{Ovarian maturation induction by RNA interference}

The use of double-stranded RNA (dsRNA) molecules to silence hormonal transcripts by RNA interference (RNAi) has also been considered as an alternative technique to eyestalk ablation of penaeids. The dsRNA is a regulatory mechanism of gene expression in many eukaryotes, but first discovered in plants (Hannon, 2002; Matzke and Matzke, 1995; Ratcliff et al., 1997). Initial observations indicated that both sense and antisense RNAs triggered the gene silencing (Fire et al., 1991; Guo and Kemphues, 1995). Later, it was demonstrated that the dsRNA mixture was more potent as a trigger to sequence-specific suppression of its cognate messenger RNA (mRNA) (Fire et al., 1998). Several genetic studies in the nematode worm Caenorhabditis elegans were decisive for the understanding of the mechanism underlying dsRNA-induced gene silencing (Fire et al., 1998; Timmons and Fire, 1998; Timmons et al., 2001), becoming a currently well-developed tool for functional genomics.

The natural production of dsRNA has been attributed to several biological processes involving gene regulation, antiviral responses, transposons suppression and heterochromatin formation (Aravin et al., 2007; Denli and Hannon, 2003; Riddle and Elgin, 2008; Li and Ding, 2005). Meister and Tuschl (2004) presented a comprehensive review on the mechanisms of the RNAi.

The RNAi technology consists of the artificial introduction of long dsRNAs or short interfering RNAs (siRNAs), aiming to inactivate gene expression in both cultured cells and living organisms (Meister and Tuschl, 2004). After in vitro synthesis of gene-specific dsRNA molecules, the administration has been successfully done by injection, feeding or engineered virus and bacteria in different organisms (Hannon, 2002). Another interesting property of the RNAi is the possibility to amplify the silencing signal, producing de novo dsRNA molecules (Tijsterman et al., 2002). Also, it has been demonstrated that the exposure to dsRNA molecules can cause transgenerational gene silencing (Burton et al., 2011; Devanapally et al., 2015). Considering these properties of the RNAi technology, it has been referred as a new promising tool for developing an approach for sustainable shrimp cultivation (Phetrungnapha et al., 2015).

In addition to the studies on hormonal transcripts silencing as an alternative technique to eyestalk ablation, the RNAi technology has been widely applied in other areas of shrimp culture. For example, there are efforts available in the literature on antiviral therapy, gene regulation on carbohydrates metabolism, osmoregulation, molt, immunology, growth and sexual differentiation (Hui et al., 2008; Lugo et al., 2006; Shockey et al., 2009; De Santis et al., 2011; Tiu et al., 2007; Ventura et al., 2009). However, further investigations are required to develop feasible techniques for transferring to the industry.

The application of the RNAi technology on penaeids gonadal maturation are focused on two of the most important species for the aquaculture industry, P. monodon (closed thelycum) and L. vannamei (open thelycum). First of all, molecular characterization of sinus gland peptides having vitellogenesis-inhibiting activity, the GIH and the vitellogenin cDNA, was conducted for these species (Raviv et al., 2006; Tsutsui et al., 2007; Treerattrakool et al., 2008). For P. monodon, Treerattrakool et al. (2008) demonstrated in vitro the influence of GIH on Vg transcripts levels in the ovary using GIH-specific dsRNA. These results highlighted the potential of dsRNA-mediated gene silencing as a powerful tool for more ethical shrimp gonadal maturation.

Concerning in vivo bioassays, Treerattrakool et al. (2011) injected GIH-dsRNA molecules in both wild and domesticated $P$. monodon females at concentration of $3 \mu \mathrm{g} / \mathrm{g}$ of body weight. The injection inhibited GIH transcript, which lasted for a minimum of 30 days. Although spawning of dsRNA GIH-injected domesticated females was recorded (14\%), $57 \%$ of the animals did not show gonadal development, whereas $53 \%$ of the eyestalk-ablated females spawned. Better results were found using wild females. Sixty three percent $(63 \%)$ of the dsRNA GIH-injected females spawned, but the spawning percentage was lower than that for eyestalk-ablated females $(72 \%)$. The authors attributed this difference to the culture conditions because wild and domesticated shrimp were reared in different systems. Thus, factors such as size, age, water quality, and nutrition might have affected the reproductive performance.

Later, Treerattrakool et al. (2013) tested the efficiency of knockingdown GIH transcript by oral feeding with $0.3 \mathrm{~g}$ wet weight of adult Artemia salina enriched with GIH-expressing Escherichia coli four times per day. Females were initially divided into three treatment groups: GIH dsRNA injection; GIH dsRNA-Artemia; and Artemia (without GIHexpressing E. coli). The treatment GIH dsRNA-Artemia showed a significant decrease in GIH transcript level in comparison with Artemia. However, the suppression of GIH transcript by feeding was less effective than the injection method.

For L. vannamei, Feijó et al. (2016) did not observe spawning of dsRNA GIH-injected domesticated females. However, the authors demonstrated the efficiency of the dsRNA-GIH injection to knockdown the GIH transcript. An interesting result reported by these authors is that a reduction of the eyestalk GIH mRNA levels from the 15th dpi (day postinjection) was observed, whereas the expected increase in the ovarian vitellogenin mRNA expression was recorded only on the 37th dpi. The authors attributed this late response of GIH silencing on the expression of vitellogenin mRNA to be associated with residual concentrations of GIH in the sinus gland and circulating in the hemolymph since mRNA silencing by dsRNA only inhibits the synthesis of new hormone molecules. On the other hand, the eyestalk-ablated females did not show variation in the GIH expression in their remaining eyestalk throughout the trial period although spawning events were recorded. 
Thus, the investigations have demonstrated the potential of the RNAi technology to silence GIH transcripts. However, it is possible to note that the underlying mechanisms of GIH synthesis involved in the shrimp gonadal maturation are not fully understood (Feijó et al., 2016). In addition to the genomics of ovarian maturation, further efforts should target aspects, such as: (1) simultaneous GIH-transcript silencing in different structures that synthesize the hormone; (2) development of techniques to deliver effectively the dsRNA molecules via engineered microorganisms included in practical diets or probiotics; (3) growth performance of the offspring produced from dsRNA-induced females; (4) heritability of GIH silencing by RNAi; (5) evaluation of the lifetime and reuse of dsRNA-induced females; (6) economic evaluation of the production having broodstock lasting longer and better selling prices of the larvae produced under more ethical conditions. These aspects could make the technology interesting for the industry against the cruel, but cheaper eyestalk ablation.

\section{Polyploidy culture}

The induction of polyploidy in penaeid shrimps offers an alternative for improving growth rates, sterility and genetic protection. A commercially important consequence of this technology is the skewed sex ratio towards females that was demonstrated in $F$. chinensis $(80 \% \mathrm{fe}-$ males; Li et al., 2003) and M. japonicus (100\% females; Coman et al., 2008). The culture of female shrimps has been proposed as a commercially important alternative for the industry (Ventura and Sagi, 2012) since they grow larger than males, as it has been experimentally demonstrated for P. monodon (Gopal et al., 2010) and L. vannamei (Alfaro-Montoya et al., 2016).

Sellars et al. (2010) reviewed the status of the knowledge accumulated in this field. The best-studied species are $F$. chinensis, $M$. japonicus, and P. monodon; techniques for triploid induction at meiosis I or meiosis II have been developed, and the triploid larvae are viable to adult stages. For $P$. monodon, this knowledge has been implemented in a commercial facility for evaluating the commercial yields of this technology.

Concerning tetraploid shrimps, although this condition has been effectively induced, larvae are not viable in any penaeid studied. A particular problem has been reported for L. vannamei; triploid larvae of this species have low viability. Recent efforts to improve polyploidy survival in L. vannamei using chemical and temperature shocks, induced variable rates of triploidy at embryonic stage, variable survival at nauplii stage, and total mortality beyond protozoea 3 (Sellars et al., 2012a). The high induction variability among replicates measured for L. vannamei using 6-dimethylaminopurine (6-DMAP) is another problem registered for this species.

Laboratory experimental data indicate that survival rates of triploid larvae are lower than diploid larvae for $F$. chinensis and M. japonicus. The growth of postlarvae is similar between triploids and diploids during juvenile stages, but it is higher for triploids at reproductive age in $F$. chinensis, generating a $9 \%$ increase in body weight $(14.0 \mathrm{~g})$ at $10 \mathrm{~cm}$ body length (Xiang et al., 2006). These authors did not evaluate differential growth between sexes, but a higher proportion of triploid females could be responsible for the higher growth rate reported. In $M$. japonicus no growth differences between triploid and diploid animals were measured (Coman et al., 2008). However, experimental data were collected up to $20-25 \mathrm{~g}$ body weight, and complementary evaluations from P. monodon (Gopal et al., 2010) and L. vannamei (Alfaro-Montoya et al., 2016) suggest that growth differences between sexes are dramatically evident after reaching $30 \mathrm{~g}$ body weight.

Recent findings from $P$. monodon indicate that triploidy does not skew sex ratio towards females (Sellars et al., 2012b); on the contrary, sex ratio of triploids was 1 female: 1.625 males. This finding has profound scientific implications concerning the mechanism of sex determination and differentiation in penaeid shrimps. Genetic protection, on the other hand, is a major advantage of triploid shrimps since reproductive sterility has been demonstrated (Sellars et al., 2012a).

\section{Hybrid culture}

The culture of hybrid shrimps is another alternative for improving yields in commercial operations based on the principle of hybrid vigour induced by a positive heterosis. Hybridization vigour can be achieved intra-specifically, mating individuals of different strains of the same species or inter-specifically, mating individuals of different species (Fazhan et al., 2017).

Inter-specific hybridization in penaeid shrimps has received some attention; however, this line of research and development is not advancing as the other lines covered in this review. Benzie et al. (2001) reported the first comprehensive evaluation of the quality of hybrids between $P$. monodon and Penaeus esculentus. Their findings indicate that hybridization induced a low hatch rate $(<4 \%)$, no differential survival at 4 weeks, no hybrid vigour, and similar growth rate to $P$. monodon. Sex ratio of hybrids was skewed towards males (86\%) with an intermediate color pattern from parental species. So far, Lin et al. (1988) reported the best hybrid hatch rate for $P$. monodon $\times$ Penaeus penicillatus (30\%); however, hybrid vigour requires confirmation.

Attempts at producing inter-specific hybrids between other penaeid shrimps have generated poor or no hatch rates. Low fertilization $(<1 \%)$ was reported for Litopenaeus setiferus $\mathrm{x}$ L. stylirostris (Lawrence et al., 1984) and L. setiferus $\mathrm{x}$ Litopenaeus schmitti (Bray et al., 1990b). No fertilization was reported for L. setiferus $\mathrm{x}$ L. vannamei (Misamore and Browdy, 1997), L. stylirostris x L. vannamei (Perez-Velazquez et al., 2010; Ulate and Alfaro-Montoya, 2010), Litopenaeus occidentalis x L. vannamei (Ulate and Alfaro-Montoya, 2010), and reciprocal L. occidentalis $\mathrm{x}$ L. stylirostris (Ulate and Alfaro-Montoya, 2010).

It seems that these negative reports have influenced the scientific interest for studying the biological constrains associated with penaeid hybridization. Benzie et al. (2001) stated that the major problem to hybrid production was fertilization and hatching of eggs; therefore, a new approach is needed for understanding and improving hybrid hatch rates as proposed by Ulate and Alfaro-Montoya (2010). These authors suggested the study of the inter-specific mechanism of sperm-egg compatibility.

Based on our current knowledge concerning the fertilization mechanism of penaeid shrimps, the following stages have to be identified in inter-specific crosses: a) the vitelline envelope of ovulated eggs must recognize and bind to the tip of spermatozoa's spikes as the first requirement. This can be measured with the primary binding model proposed by Rojas and Alfaro (2007); b) the cortical reaction of ovulated eggs must induce the acrosome reaction of capacitated spermatozoa. This can be measured with the egg water technique developed by Griffin (1987); c) spermatozoa must be capacitated intra-specifically in the thelycum of the same species based on Alfaro et al. (2007), Aungsuchawan et al. (2011), and Braga et al. (2014). So far, hybridization has been attempted by artificial insemination, but with the future improvement of the in vitro fertilization technique (section 10), this approach will also contribute to the general understanding of interspecific fertilization barriers.

\section{Female monosex culture}

The all-female monosex crustacean population in animal husbandry is relevant in species in which females possess higher growth rate than males. Shrimp female monosex culture offers an alternative to the traditional mixed sex cultures. In this section, we review the most recent advances in the topic of crustacean feminization and the understanding of the sex-differentiation mechanism. Harlıoğlu and Farhadi (2017) presented a review on crustacean feminization, based on the following strategies for direct feminization: a) polyploidy induction (reviewed in section 5), b) hormone therapy, c) ablation of androgenic gland (AG), d) gene silencing by RNA interference (RNAi), and indirect 
feminization through masculinization.

The best approach to generate all-female progeny in crustaceans for commercial aquaculture has been the indirect feminization demonstrated and patented for $M$. rosenbergii at Ben Gurion University by Prof. Amir Sagi and co-workers (Levy et al., 2016). These authors demonstrated that a single injection of AG cells into $M$. rosenbergii at stages younger than PL60, induced complete sex reversal into neomales with the female genotype (WZ), that were used to produce WW females that spawn all-female (WZ) progeny. For this species, sex reversal technology has reached a commercial level, using gene silencing by RNAi, which induces feminization of males (Ventura et al., 2012) as broodstock for producing all-male postlarvae cultures. The biological principle responsible for this technology is the unique existence of the androgenic gland (AG) of crustaceans (Ventura et al., 2011).

The Penaeidae AG has been reported from some species, including Melicertus kerathurus, M. japonicus, $F$. chinensis and P. monodon. In general, these reports suggested that the AG is a cordlike cellular mass attached to the distal region of the medial vas deferens; however, a more precise anatomical organization was demonstrated for Litopenaeus and Rimapenaeus (Alfaro-Montoya and Hernández, 2012; AlfaroMontoya et al., 2016). These contributions found a gland-like structure located at the distal terminal ampoule and a blood vessel associated with the vas deferens; the mass of cells is organized in grape-like clusters as reported for other penaeid shrimps (Li and Xiang, 1997; Mareddy et al., 2011; Li et al., 2012; Vázquez-Islas et al., 2014).

The AG specific insulin-like peptide (IAG) plays a central role in sexual differentiation of decapod crustaceans (Sagi et al., 1997; Ventura and Sagi, 2012). Complete sequences of IAG cDNA have been reported for three Asian shrimps: P. monodon, M. japonicus and F. chinensis (Li et al., 2012) and one American species: L. vannamei (Vázquez-Islas et al., 2014). Partial sequences were reported for the American species: L. stylirostris and L. occidentalis (Sancho-Blanco et al., 2018).

Androgenic gland ablation and implantation technologies were evaluated in L. vannamei (Alfaro-Montoya et al., 2016; Vega-Alpízar et al., 2017). However, no complete sex reversal of postlarvae starting at PL34 was induced, but significant changes associated with sexual physiology were observed in andrectomized males and AG implanted females. These studies have demonstrated that L. vannamei responds differently to AG ablation since males are capable of regenerating appendices and sexual structures, namely petasmas and appendices masculinae, in the absence of AGs. AG deprived males regenerated smaller petasmas and appendices masculinae than normal males; this observation is contrary to the findings reported for $M$. rosenbergii and $F$. chinensis (Alfaro-Montoya et al., 2016). AG implanted females developed some minor alterations in endopodites of first pleopods suggesting some minor degree of masculinization (Vega-Alpízar et al., 2017). Therefore, sexual plasticity seems to be different between Dendrobranchiata and Pleocyemata.

In the Pleocyemata: $M$. rosenbergii, Aflalo et al. (2006) determined that males were completely and functionally sex-reversed (neofemales) by surgery. Additionally, microsurgical extirpation of AGs of males from an Indian strain in early stages of development (PL15 to PL30) exhibited full and functional sexual reversion towards feminization, capable of mating with normal males (Aflalo et al., 2014).

Due to the ability of IAG to regulate sexual characters in crustaceans, the post-transcriptional gene silencing of IAG messenger can feminize males via dsRNA-injection approach (Rosen et al., 2010), to achieve monosex populations in crustaceans of commercial interest. For the first time, Ventura et al. (2012) accomplished the complete and functional sex reversal of $M$. rosenbergii through in vivo Mr-IAG silencing, generating neofemale prawns with full reproduction characteristics (Sagi et al., 2013). RNAi technology is a powerful tool for biotechnological applications in shrimp aquaculture (Nguyen et al., 2018a, 2018b). Recently, Priyadarshi et al. (2017) demonstrated that IAG knockdown through plasmid-based constructs (pcD-IAG-lh: expressed long hairping RNA) injected directly in sexually mature $M$. rosenbergii males, inhibited the transformation of adult orange claw (OC) to blue claw (BC) morphotype males, breeding in community. The authors proposed a significantly higher morphotype transformation, triggered by means of augmentation of IAG transcripts (pcD-IAGorf plasmid injections: open reading frame with strong constitutive promoter).

The hormone and neurotransmitter treatment approach has received less attention than the IAG approach. However, some interesting data have been obtained in $M$. rosenbergii (Baghel et al., 2004; Ohs and Petrie-Hanson, 2006; Gunamalai et al., 2006), Emerita asiatica (Gunamalai et al., 2006), Penaeus semisulcatus (Aktas and Gene et al., 2011) and Astacus leptodactylus (Malati et al., 2013; Harlıoğlu et al., 2017). The strategies used to experimentally test feminization vary from 17 $\alpha$-methyl testosterone bioencapsulation (hormone-enriched Artemia as food), dopamine dietary administration, to water bath immersion or injection of $17 \beta$-estradiol. These therapies based on steroids proved to be effective in generating several changes in physiological responses associated with the control of female reproduction in crustaceans (Harlıoğlu and Farhadi, 2017). Recent findings reported by Harlıoğlu et al. (2017) indicate that 75\% feminization of Ascatus leptodactylus is induced by injecting $17 \beta$-estradiol at $10^{-7} \mathrm{~mol} /$ crayfish), complemented with hormone bath at $50 \mu \mathrm{g} / \mathrm{l}$ for pleopodal eggs and juveniles at stages 1 to 3 .

Concerning penaeid shrimps, the study of Bin Bahar (2016) on Fenneropenaeus merguiensis found that complete sex reversal to females was induced in postlarvae by feeding $17 ß$-estradiol at $1600 \mathrm{mg} / \mathrm{Kg}$ diet. Additionally, Aktas and Gene (2011) reported some feminization in Penaeus semisulcatus at egg and nauplii stages by $17 \beta$-estradiol immersion at $50 \mu \mathrm{g} / \mathrm{l}$.

These findings suggest that $17 \beta$-estradiol is capable of reversing the sex in decapod crustaceans before the sexual differentiation window. Therefore, the normal mechanism based on the AG development and activity seems to be interrupted by $17 \beta$-estradiol; more research is needed to understand these observations.

\section{Gametes, embryos and nauplii cryopreservation}

Cryopreservation is a recurrent aquaculture subject addressed in the literature due to its potential as a tool for genetic material preservation (Benzie, 1998; Hulata, 2001; Tiersch and Green, 2011). Most of the efforts have been done for sperm of several aquatic animals (Akarasanon et al., 2004; Hassan et al., 2015; Liu et al., 2014; Suquet et al., 2000; Tiersch et al., 2007). Hybridization, selection breeding, gynogenesis, domestication and conservation of stocks have been referred as the main implications of banking cryopreserved semen (Gwo, 2000).

Among penaeids, sperm cryopreservation has been attempted for only few species, such as L. vannamei, $L$. schmitti and $P$. monodon (Castelo-Branco et al., 2014; Nimrat et al., 2005, 2006). Chilling, freezing and vitrification are the techniques evaluated for sperm preservation (Castelo-Branco et al., 2015, 2018; Morales-Ueno et al., 2013; Vuthiphandchai et al., 2007). Also, the preservation of spermatophore, sperm mass, sperm suspension and cadaveric sperm have been addressed in the literature (Bart et al., 2006; Castelo-Branco et al., 2016; Lezcano et al., 2004). However, most of the reports on this matter addressed evaluations on the toxicity of cryoprotectants or the efficiency of extenders (for review, see the references cited above in this paragraph). Testing cryoprotectants and extenders provides fast results. Demonstration of the efficiency of cryopreservation protocols has been neglected, especially those based on long-term storage. In fact, sperm cryopreservation is not a reality for the penaeid culture industry.

It is important to highlight that the unsuccessful application of sperm cryopreservation at industrial levels is also related to some reproductive aspects of penaeids. For example, the spermatozoal capacitation and, the consequent difficulty to obtain high hatching rates by in vitro fertilization. These subjects will be addressed in detail on the next topic of this review. Briefly, the spermatozoon undergoes changes 
during storage of the spermatophore in the thelycum, acquiring capacity to fertilize the egg (Alfaro et al., 2003, 2007; Braga et al., 2014). It is well-known that these changes include ionic exchanges between spermatozoa and thelycum, activating biochemical pathways that result in morphological rearrangements (Aungsuchawan et al., 2011; Braga et al., 2013). Despite the knowledge of this phenomenon for penaeids, there is no technique developed to in vitro capacitate spermatozoa without the need for previous storing in the thelycum. The use of noncapacitated spermatozoa explains why low fertilization rates are obtained by in vitro fertilization. Thus, having cryopreserved sperm collected from terminal ampoule would not guarantee high fertilization or hatching rates without storing them in the thelycum.

The evaluations on the capacity of cryopreserved sperm to fertilize eggs available in the literature are based on artificial insemination. For example, Morales-Ueno et al. (2013) showed that about $60 \%$ of the artificially inseminated females have successfully produced nauplii after chilling of L. vannamei sperm mass for $4 \mathrm{~h}$ at $23^{\circ} \mathrm{C}$ using a modified version of the artificial extender described by Leung-Trujillo and Lawrence (1991). Castelo-Branco et al. (2018) reported the first evaluation of the efficiency of cryoprotectants for L. vannamei sperm vitrification by artificial insemination. Although these authors found zero hatching rates using vitrified sperm most likely due to spermatozoal DNA fragmentation, fertilization rates varying between 54 and $74 \%$ were recorded. For $P$. monodon, high fertilization (71-88\%) and hatching rates (63-88\%) have been reported using chilled and frozen spermatophores for artificial insemination (Nimrat et al., 2005; Bart et al., 2006; Vuthiphandchai et al., 2007). These results show that cryopreservation has potential as a tool for larval production in commercial hatcheries. However, the production based on artificial insemination using cryopreserved sperm will still require labor, space and associated costs for the management of broodstocks. Thus, most hatcheries organize their production on both sexes-based conventional systems, which include collection/production, transportation and maintenance of broodstock.

Embryos and nauplii cryopreservation have been considered as an alternative tool. First of all, because the dependency on techniques such as natural and artificial insemination could be reduced. As commented by Alfaro et al. (2001), cryopreservation of penaeid shrimp seedstock also would make international trading more economical and efficient. Currently, international trade for penaeids is based entirely on nauplii and postlarvae shipping, which requires packing in large amount of seawater. Therefore, investors are eventually paying for the weight of the water in addition to the larvae price. This is one of the reasons some investors prioritize the location of the larval supplier instead of adopting good culture practices protocols and ensuring the quality of the produced larvae. This strategy for reducing production cost is usually associated to failed crops due to issues of health and/or growth.

As well as for sperm cryopreservation, the main efforts published for embryos and larvae address evaluations on the toxicity of cryoprotectants (Alfaro et al., 2001; Diwan and Kandasami, 1997; Dong et al., 2004). The authors of these studies have agreed that the toxicity of cryoprotectant is dependent on species, developmental stage, type, concentration and equilibration time (Gwo and Lin, 1998; Newton and Subramoniam, 1996; Vuthiphandchai et al., 2005). Despite these contributions, cryogenic protocols for penaeid embryos and larvae have not yet been developed.

The relevance of testing cryoprotectants is related to the fact that cryopreservation often involves the use of these solutions, which protect cells from damage during freezing and thawing. In addition to the type of cryoprotectant (permeating or non-permeating), its concentration has to be considered. Also, cryoprotectants are usually toxic to cells and, therefore, the balance between protection and toxicity will determine the optimal concentration. Another important factor to be considered is the equilibration time, which may be defined as the time of exposure to the cryoprotectant before freezing required to allow optimal permeation while minimizing toxicity (Fuller, 2004; Hagedorn et al., 1997; Tiersch et al., 2007).

Methanol, ethanol, ethylene glycol (EG), dimethyl sulfoxide (DMSO), formamide, acetamide, glycerol, propylene glycol and polyethylene glycerol are examples of permeating cryoprotectants tested for penaeids, whereas glucose, fructose, sucrose and trehalose are the nonpermeating solutions evaluated. Methanol and EG were reported as least toxic for $F$. indicus morula and nauplii (Simon et al., 1994; Newton and Subramoniam, 1996). Likewise, EG is least toxic (30\% $v / \mathrm{v}$ for $20 \mathrm{~min}$ ) for L. vannamei larvae due to low osmolality and high permeability (Dong et al., 2004). For P. monodon embryos, DMSO, acetamide, glycerol and sucrose were less toxic. These findings demonstrate that it is not possible to define the best cryoprotectant to be used for penaeid cryopreservation because the toxicity is species and developmental stage dependent. Although some authors suggested that low molecular weight cryoprotectants perform better due to higher permeation into the cell (Gwo and Lin, 1998; Simon et al., 1994).

After cryoprotectant exposure, the cells will dehydrate during the freezing due to increased salt concentration (Tiersch et al., 2007). It has been suggested that embryo dehydration is probably more important for successful cryopreservation than the amount of cryoprotective agent present in the cell (Kuleshova et al., 2001). Two methods have been applied to produce osmotic dehydration: (1) nonequilibrium, i.e. vitrification, in which the cells are immersed directly into liquid nitrogen, changing rapidly their state from liquid to "glassy"; (2) equilibrium, based on controlled and slow freezing and thawing. Both methods require the removal of cell water, the introduction of cryoprotectants and the subsequent removal of these compounds from the embryos (Saragusty and Arav, 2011). Therefore, the cell to be cryopreserved must be permeable to water and cryoprotectants. The complex membrane system composed by an outer hatching envelope and an inner ooplasma has been mentioned as the main obstacle to cryoprotectant permeation into penaeid embryos (Gwo and Lin, 1998; Simon et al., 1994).

The membrane permeabilization of penaeid embryos has not been a matter of agreement in the literature. Some authors have reported evidences that the hatching envelope behaves as a barrier to intracellular cryoprotectants (Gwo and Lin, 1998; Simon et al., 1994). This is a point of disagreement for other authors based on morphological analysis that showed membrane shrinking and re-expanding, and reduced hatching rates obtained when embryos were exposed to cryoprotectants (Newton and Subramoniam, 1996; Vuthiphandchai et al., 2005). It seems to us that this disagreement is actually a relativization issue. For example, Simon et al. (1994) commented that successful cryopreservation of fish and oyster embryos demands low cryoprotectant concentrations than those attempted for penaeids. Thus, the membrane complex of penaeids would show lower permeabilization to cryoprotectants than other aquatic animal groups. Most important is that permeabilization of the hatching envelope seems to be a key matter to be further investigated in order to develop an efficient cryogenic protocol for penaeid embryos.

A well-known feature of the membrane complex of penaeid eggs and embryos is its greater flexibility at low temperatures and, thus, resistance to cooling in comparison to other animals, such as mammals (Lin et al., 2013). Alfaro et al. (2001) presented a detailed explanation, which is transcribed below:

"Decapod crustacean produce heavily yolked eggs, which accumulate phospholipid droplets containing polyunsaturated fatty acids (PUFAs; Harrison, 1990; Ravid et al., 1999). These lipid classes are associated with the survival of embryos and initial larval stages of marine shrimp; crustacean phospholipids generally contain low $\omega-6$ but high $\omega-3$ levels of PUFAs (Eicosapentaenois acid 20:5 $\omega-3$ and Docosahexaenoic acid 22:6 $\omega-3$; Harrison, 1990); on the other hand, PUFAs from mammals are made by $\omega-6$ fatty acids (Chapelle, 1986). The high levels of these two fatty acids in marine animals is believed to be related to the effective unsaturation of the melting point of a lipid; the $\omega-3$ structure allows greater degree of unsaturation than the $\omega-6$ 
or $\omega-9$, so that crustacean phospholipids permit a better flexibility of membrane structure at lower temperatures (Chapelle, 1986)".

Despite the higher membrane flexibility than that of mammals, penaeid embryos have demonstrated high sensitivity to cooling injury that prevents successful cryopreservation, which may be caused by factors other than lipid composition, such as permeabilization of the membrane to cryoprotectants as commented above.

Issues on cryoprotectants permeation and, consequently, dehydration are also reported for fish embryos. The main reason given is the large size of these embryos, which may interfere the uniform permeation of cryoprotectants (Hagedorn et al., 1997). Therefore, dehydration before freezing has been attempted in order to improve survival (Robertson et al., 1988). Although the size of the crustacean eggs and embryos is smaller than those of fish, Alfaro et al. (2001) evaluated the sensitivity of penaeid embryos to a hypersaline treatment at $12{ }^{\circ} \mathrm{C}$ as a technique to be developed for dehydration before freezing. Still concerning the issues on cryoprotectant permeation, permeating and nonpermeating solutions have been tested separately for penaeids. The combination of both types of cryoprotectants provided higher survival rate of Macrobrachium amazonicum embryos submitted to $2{ }^{\circ} \mathrm{C}$ for $2-6 \mathrm{~h}$ (Ferreira et al., 2015, 2017). Therefore, research efforts on dehydration before freezing, efficiency of solutions combing both types of cryoprotectants, as well as vitrification, could be important contributions on the permeabilization of the membrane.

Embryos have been often evaluated in studies on cryopreservation for penaeids. Several developmental stages from early to advanced embryos have been studied for eight species. Among larval stages, nauplius is frequently evaluated, whereas the cryopreservation of protozoea has been investigated for only $M$. japonicus and L. vannamei (Dong et al., 2004; Gwo and Lin, 1998). In general, better results are obtained using embryos and larvae at advanced developmental stages, which show higher resistance to cryoprotectant toxicity and to cryopreservation than early stages (Alfaro et al., 2001; Simon et al., 1994; Vuthiphandchai et al., 2005).

Early embryonic stages are usually preferred for cryopreservation in mammals, whereas it seems to be the opposite for fish and shellfish (Chao and Liao, 2001). For fish, one of the reasons given is that eggs and embryos contain a large amount of yolk (Zhang and Rawson, 1996). Embryos of penaeid also show large proportional amount of yolk, which may lead to the formation of ice crystals, which will cause damage to the egg structure (Diwan and Kandasami, 1997; Ferreira et al., 2017; Newton and Subramoniam, 1996). On the other hand, nauplii and protozoea stages compared to embryos contain lower yolk content (Dong et al., 2004). In addition, it has been demonstrated that shrimp larvae have higher tolerance to cryoprotectant toxicity than embryos most likely due to higher permeation of cryoprotectants related to the decreasing in the complexity of the membrane system and the amount of yolk (Alfaro et al., 2001; Dong et al., 2004; Tsai and Lin, 2009). Therefore, nauplius has been previously considered a suitable stage for cryopreservation (Newton and Subramoniam, 1996).

Besides the higher tolerance to cryoprotectants, the use of larval stages for cryopreservation instead of embryos would have the advantage for reducing the chances of failure embryonic development and/or hatching. The embryological events are not fully understood for penaeids, but it is known that embryos with normal morphology are not a guarantee for hatching. For example, Gwo and Lin (1998) reported that embryos at the blastocele stage treated with some cryoprotectants continued to develop up to the prenauplius stage, remaining active inside the vitelline membrane, but were unable to hatch. It is possible to note that the higher tolerance of larvae to cryoprotectants will not necessarily lead to better results in cryopreservation. Thus, further investigations are required to evaluate the suitability of larval stages for cryopreservation in penaeids.

\section{In vitro fertilization}

All penaeids show external fertilization, which is initiated after spawning. During the oviposition, females release oocytes through the genital pores located on the coxae of the third pair of pereiopods. Simultaneously, spermatozoa are enzymatically released from sperm mass stored in the thelycum. Females externally mix gametes with the swimming movements of the pleopods, initiating the interactions among them (Dall et al., 1990).

Fertilization begins when spermatozoal spike recognizes and attaches itself to the egg coat (Clark et al., 1981; Wikramanayake and Clark, 1994). This initial contact is facilitated by the affinity of receptors on the spike tip for specific vitelline envelope ligands of the oocytes (Chen et al., 1994). A visible acrosomal reaction (AR) takes place, which consists of biochemical, ionic, and morphological changes in the acrosomal complex necessary for spermatozoal incorporation into the egg to complete successful fertilization (Gwo, 2000). The AR is initiated with spike depolymerization via acrosomal vesicle rupture and ends with the exocytosis of cell contents (Braga et al., 2013).

The biochemical and ionic pathways that control the penaeid fertilization is poorly understood. It is known that penaeid fertilization is affected by the enzyme trypsin. For example, Pongtippatee et al. (2007) suggested that this enzyme breaks down the egg coat and enables the incorporation of the $P$. monodon spermatozoon. For the same species, Kruevaisayawan et al. (2008) identified trypsin as the enzyme involved in the degradation of the egg coat, the fusion of the membranes of the gametes, the AR, and the incorporation of the spermatozoa. This limited knowledge prevents advances on the development of techniques for penaeid in vitro fertilization.

The potential of in vitro fertilization for the shrimp farming industry is mainly related to the improvement of breeding programs. For example, the application of this technique is useful to the hybridization of penaeid shrimp (Misamore and Browdy, 1997; section 7). Also, the integration of seedstock cryopreservation and in vitro fertilization could reduce the number of broodstock to be kept in captivity, representing a reduction of costs for commercial hatching.

Despite its potential, only few investigations have evaluated the in vitro fertilization in penaeids. Clark et al. (1973) described the first report of in vitro fertilization by dissecting Farfantepenaeus aztecus mature females and duplicating the gametes external mixing. The authors did not mention the fertilization rate, but a $10 \%$ hatching rate was reported. Later, Nair (1987) obtained $42 \%$ hatching rate with $F$. merguiensis in vitro fertilization using eggs collected by dissection of mature females; however, in this species, Ikhwanuddin et al. (2015), using also dissection of ovaries (ovulated eggs) and spermatozoa from males, obtained $3 \%$ hatching rate in calcium-free saline solution. Other authors have reported techniques based on the removal of females at the time of spawning for collecting eggs in Petri dishes or fertilization funnels, keeping the animals still alive and, thus, available for further using (Misamore and Browdy, 1997; Rojas and Alfaro, 2007). Misamore and Browdy (1997) obtained $2.48 \%$ and $3.88 \%$ fertilization-hatching rate for L. setiferus and L. vannamei, respectively.

The limitation of in vitro fertilization demonstrated by the low hatching rates obtained by Clark et al. (1973), Nair (1987), Misamore and Browdy (1997), and Ikhwanuddin et al. (2015) is most likely related to processes undergone by the spermatozoa before fertilization. Eggs also undergo a process before fertilization, which is named egg activation or cortical reaction and comprises a release of jelly precursor from the cortical crypts, transformation of the precursor material into a jelly layer, exocytosis of cortical vesicles, and formation of the hatching envelope (Lynn et al., 1992). Both unfertilized and fertilized eggs undergo these modifications (Pillai and Clark, 1987). The eggs activation is dependent on an intracellular $\mathrm{Ca}^{2+}$ wave induced by seawater $\mathrm{Mg}^{2+}$ in Sicyonia ingentis (Lindsay et al., 1992). For penaeids, egg activation is also easily induced by the contact of the gamete with seawater (Rojas and Alfaro, 2007). Thus, this water-activated process undergone by 
female gametes is a unique mechanism that interferes with the timing for mixing gametes, affecting the design of in vitro fertilization techniques since sperm-egg interaction should occur before egg activation.

On the other hand, spermatozoa undergo a capacitation process, which consists of biochemical, physiological and morphological modifications that provide the gamete with capacity to fertilize the egg. These modifications have been reported only after the storage of the spermatophore within (closed thelycum) or while adhered to (open thelycum) the female thelycum (Alfaro et al., 2003; Braga et al., 2014). The disability of spermatozoa directly extruded from the terminal ampoule to fertilize the egg has been demonstrated by lower fertilization rates compared to those obtained when spermatozoa are previously stored in the thelycum (Bray and Lawrence, 1992; Alfaro et al., 1993). Also, low or zero rates of in vitro induction of the acrosomal reaction by egg water are obtained when spermatozoa collected from the terminal ampoule are used (Alfaro et al., 2003, 2007; Wikramanayake et al., 1992).

As mentioned above, the efforts on in vitro fertilization have been based on eggs collection and duplication of their externally mixing with sperm suspension obtained from freshly extruded spermatophores (Clark et al., 1973; Nair, 1987). Therefore, the low hatching rates obtained by in vitro fertilization may be a consequence of the use of noncapacitated spermatozoa. Since there is no technique developed for in vitro spermatozoal capacitation, artificial insemination has been used instead, consisting in manually storing a spermatophore into the closed thelycum or adhering the sperm mass on the open thelycum. Higher hatching rates have been achieved by using artificial insemination, but it depends on individual manipulation of both males and females, requiring the ability of technicians and usually a long-spent time at commercial scale.

Thus, the successful development of techniques for in vitro fertilization is most likely associated to the understanding of the spermatozoal capacitation and the control of egg activation. The morphological modification undergone by the spermatozoa during the capacitation has been widely described at ultrastructural level for penaeids (Alfaro et al., 2007; Aungsuchawan et al., 2011; Braga et al., 2014). Also, it is known that those morphological modifications actually correspond to the final stage of the capacitation. At the beginning of this process, ionic exchanges between membranes of the sperm mass and thelycum activate biochemical pathways, which, trigger the morphological rearrangements (for review, see Braga et al., 2013). The development of techniques to replicate in vitro the sequence of spermatozoal capacitation and to control the process of egg activation could make possible the in vitro fertilization, which represents an important advance for the improvement of penaeid broodstock genetics and management.

\section{Genetic improvement: a molecular approach}

11.1. Molecular markers in penaeids: marker-assisted selection (MAS) and genome-wide markers selection (GS)

The genetic improvement of breeding schemes for penaeid shrimps has been facilitated by molecular markers for the artificial selection of individuals with traits of commercial interest such as disease resistant genes, genetic diversity, population structure and kinship traceability.

The primary marker-assisted selection employed for shrimp breeding programs, focusing in PCR-based techniques, are microsatellites/minisatellites, single nucleotide polymorphism (nuclear DNA), and mitochondrial (mtDNA) markers, based on molecular genetic variations.

Munang'andu and Evensen (2017) summarize growth and performance traits using microsatellites, single nucleotide polymorphism (SNP) and quantitative trait locus (QTL), in M. japonicus, L. vannamei, $P$. monodon and $F$. chinensis, demonstrating some advantages in molecular genetics for selective breeding and reproduction.

In the case of $M$. japonicus, new microsatellites (SSRs) were identified by next-generation sequencing (NGS) through a strategy called genome survey sequencing (GSS), with high efficiency results (Lu et al., 2017). These SSRs could be used in population genetics, parentage analysis, genetic-association mapping, QTL and marker-assisted selection (MAS). P. vannamei breeding lines of domesticated strains used in hatcheries from China were analyzed by SSR DNA markers to obtain broad patterns of genetic diversity and population structure. These results showed evidence of multiple genetic sources: MexicoEcuador, Hawaii, Southeast Asia-Thailand and Panamá-Colombia (Ren et al., 2018).

In contrast, breeding and wild populations of $F$. chinensis collected from Korean West Coast, the Bohai Sea and the Yellow Sea exhibited high genetic diversity but a positive inbreeding coefficient inducing a reduction of the environmental adaptive capacity and/or disease resistance (Song et al., 2018). These findings demonstrate that microsatellites are a powerful tool for hatchery stock management, establishing programs of breeding improvement.

The use of nuclear (SSR) and mtDNA molecular markers (12S rDNA, 16S rDNA, cytochrome $b$ and control region) for developing genetic linkage maps has many limitations. These techniques are time consuming, with high cost/effort per return of polymorphisms, and show back mutation cases. The availability of high-density maps and genomewide coverage of aquaculture models is insufficient to supply information for improvement programs (Maqsood and Ahmad, 2017; Liu and Cordes, 2004; Diwan et al., 2018). However, the complete mitochondrial information of decapod crustaceans would provide a genomic resource for mitogenomic phylogeny, comparative gene arrangement and annotation (Zhong et al., 2018; Shen et al., 2007; Table 1).

The gene mapping tool for penaeids is directed to locate and characterize structurally in the genomes, several quantitative trait loci linked to phenotypic characteristics of shrimp farming relevance such as growth, disease resistance, sex determination and cold-salinity stress. Nowadays, genomic information usable to design a genetic map is based on the following approaches: single nucleotide polymorphism (SNP) genotyping, RNA-Seq technology based on next-generation DNA sequencing platform, DNA microarrays and restriction site-associated DNA sequencing (RAD-seq).

Diwan et al. (2018) reviewed the status of genome mapping of penaeid shrimps through conventional molecular markers and NGS-based genotyping methods for improving the quantity and quality of animals with genetically superior traits for aquaculture through selective breeding. In this review the authors describe the findings about construction of integrated genetic linkage maps for breeding the following species: L. vannamei based on SNP technique (Zhi-Qiang et al., 2009; Yu et al., 2017a), transcriptome analysis by RNA-sequencing technology (Yu et al., 2014), and RAD sequencing (Yu et al., 2015). P. monodon using SNP mapping (Nicholas et al., 2014; Matthew et al., 2014). M. japonicus using RAD seq (Lu et al., 2016) and F. chinensis based on QTL approach (Liu et al., 2010; Wang et al., 2012).

At present, the use of molecular markers for genotyping, gene mapping-linkage and SNP arrays has allowed the implementation of new strategies with more coverage in the genome of penaeid species. Wang et al. (2017) showed that for a L. vannamei population, growth traits such as body weight and body length (moderate or high heritability), require a SNP high-density marker covering 23 Kilobase pair (minimum density around $3.2 \mathrm{~K}$ ) throughout the genome to perform a genomic selection (GS) with accurate prediction.

A molecular tool such as RAD sequencing technology is a NGS-based genotyping method used for SNPs localization within genomic DNA of a non-model organism with minimal genomic information available. Due to the lack of genome reference information on penaeids (Table 1), an alternative approach can be implemented. Several applications have been developed using RAD genotyping in decapod crustaceans, such as genetic diversity, population structure (Jenkins et al., 2018) and highresolution genetic linkage map focusing on reproductive traits 
Table 1

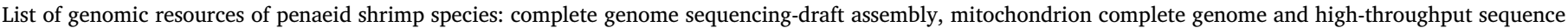
reads obtained from the National Center for Biotechnology Information (NCBI) databases (www.ncbi.nlm.nih.gov).

\begin{tabular}{|c|c|c|c|}
\hline Organism & Database collection & Accession number(s) & Reference \\
\hline \multicolumn{4}{|l|}{ Complete genome $^{1}$} \\
\hline Marsupenaeus japonicus & Genome & 24,063 & Yuan et al., 2018. \\
\hline Penaeus monodon & Genome & 12,027 & Yuan et al., 2018, Huerlimann et al., 2018. \\
\hline \multicolumn{4}{|l|}{ Mitochondrial genome $^{2}$} \\
\hline Marsupenaeus japonicus & Nucleotide & AP006346, MG772559, NC_007010 & Yamauchi et al., 2004; Zhong et al., 2018. \\
\hline Fenneropenaeus chinensis & Nucleotide & NC_009679 & Shen et al., 2007. \\
\hline Fenneropenaeus indicus & Nucleotide & NC_031366 & $\mathrm{N} / \mathrm{A}$ \\
\hline Fenneropenaeus penicillatus & Nucleotide & NC_026885 & Zhang et al., 2015. \\
\hline Fenneropenaeus merguiensis & Nucleotide & KР637168 & Zhang et al., 2016. \\
\hline Litopenaeus vannamei & Nucleotide & DQ534543, KT596762, NC_009626 & Shen et al., 2007; Liu et al., 2016. \\
\hline Litopenaeus stylirostris & Nucleotide & EU517503 & Gutiérrez-Millán et al., 2002; Peregrino-Uriarte et al., 2009 \\
\hline Parapenaeopsis hardwickii & Nucleotide & NC_030277 & Mao et al., 2016. \\
\hline Metapenaeopsis dalei & Nucleotide & NC_029457 & Kim et al., 2016. \\
\hline Parapenaeopsis hungerfordi & Nucleotide & MG873460 & $\mathrm{N} / \mathrm{A}$ \\
\hline Penaeus monodon & Nucleotide & NC_002184 & Wilson et al., 2000. \\
\hline Farfantepenaeus californiensis & Nucleotide & EU497054 & Peregrino-Uriarte et al., 2009. \\
\hline Metapenaeus ensis & Nucleotide & NC_026834 & $\mathrm{N} / \mathrm{A}$ \\
\hline Penaeus notialis & Nucleotide & $\mathrm{X} 84350$ & García-Machado et al., 1999. \\
\hline \multicolumn{4}{|c|}{ High-throughput sequence reads ${ }^{3}$} \\
\hline Marsupenaeus japonicus & SRA $^{4}$ & SRP062318, SRP108138, SRP082424. & Lu et al., 2017, Yuan et al., 2018. \\
\hline Penaeus monodon & SRA & $\begin{array}{l}\text { SRP133526, SRP108138, SRP132651, SRP009653, } \\
\text { SRP064775, SRP049934, SRP075304. }\end{array}$ & $\begin{array}{l}\text { Lu et al., 2017; Zhao et al., 2018; Yuan et al., 2018; } \\
\text { Uengwetwanit et al., 2018. }\end{array}$ \\
\hline Litopenaeus vannamei & SRA & $\begin{array}{l}\text { SRP128934, SRP062191, SRP094129, SRP136745, } \\
\text { SRP125780. }\end{array}$ & $\begin{array}{l}\text { Santos et al., 2018b; Lu et al., 2018; Jones et al., 2017; Zheng } \\
\text { et al., 2018; Zhang et al., 2018a. }\end{array}$ \\
\hline
\end{tabular}

N/A: not available.

1 Whole genome shotgun sequencing by Illumina HiSeq platform.

${ }^{2}$ Sanger dideoxy and/or Illumina sequencing.

3 DNA sequencing Illumina HiSeq platform or 454 pyrosequencing.

4 Short Read Archive (SRA) of the NCBI, linked with study accession number (SRP).

associated with commercially important phenotype characters like high-temperature tolerance, growth-related QTL and sex-determining loci (Lu et al., 2016; Yu et al., 2017b).

Another method of genotyping widely used nowadays is transcriptome analysis by RNA-sequencing technology (Santos et al., 2018a). This approach is used to identify candidate genes expressed in certain growing conditions or to locate polymorphism like SNP that can be associated with aquaculture traits. Lu et al. (2018) demonstrated that under aquaculture environments, ammonia-tolerant L. vannamei also have high disease resistance. Therefore, genetic selection in L. vannamei can be performed through detection of SNP markers located within trait-related tolerance to ammonia stress by RNA-seq technology based on the Illumina HiSeq 2500 platform (Table 1). On the other hand, using the RNA-seq approach in L vannamei, Santos et al. (2018b) evaluated commercially important traits such as growth rates and immune resistance to white spot syndrome virus (WSSV) for locating SNP linked to genes associated with innate immunity and growth. There is also a commercially available Illumina Infinium ShrimpLD-24 v1.0 BeadChip microarray containing over 6400 genome-wide SNPs based on L. vannamei. This microarray was used to obtain a genomic genebased resource for commercially important traits (Jones et al., 2017).

\subsection{Transcriptome-based discovery of pathways and differentially} expressed genes: transcriptomic information for the improvement of penaeid models

The transcriptome approach using RNA-sequencing strategy is superior over DNA microarrays since the first one provides a genome wide coverage and a high resolution of the obtained nextgen reads; additionally, a genome reference sequence is not necessary.

Transcriptome-mRNA sequencing of diverse cells or tissues subjected to different experimental treatments, life-history stages and/or physiological conditions, facilitates the acquisition of gene expression data or the identification of novel transcripts for the aquaculture improvement of decapods models. Das et al. (2016) and Havird and Santos (2016) presented the status of crustacean transcriptomics, methodologies and software analyses, which describe de novo transcriptome assembly, annotation, and differential gene expression in crustacean models.

Recent RNA-seq studies in penaeid species (Nguyen et al., 2018a, 2018b; Santos et al., 2018a) have generated new findings on this omic by de novo assembled transcriptome and annotation of protein-coding sequences. In L. vannamei, transcriptomic profiles were obtained associated with reproduction and sexual maturation, disease response, immune stimulation, and growth performance. Genomic resource for improving commercially relevant traits, reproductive biology and ovarian development were obtained for $P$. monodon. In $F$. chinensis, profiles associated with pathogen resistance and the immune mechanism were reported. Cellular immunity associated with functional characterization of hemocytes was reported for M. japonicus (Table 2).

\subsection{Genome editing in crustacean models: innovative tool for the genetic improvement of penaeids}

Findings about genomic edition by the use of the Clustered Regularly Interspaced Short Palindromic Repeats (CRISPR) technique in crustacean models is limited, and particularly in the family Penaeidae, no report has been published. The application of this technology requires the selection and design of a mutation target site based on a known sequence of interest for executing the bioinformatics to infer the gRNA (guide RNA) to be used. Therefore, it is mandatory to have a genomic resource and develop confirmatory experimental research.

Kumagai et al. (2017), Sun et al. (2017), Clark-Hachtel and Tomoyasu (2017), and Zhang et al. (2018a), presented contributions about this new molecular tool. Site directed mutagenesis techniques such as genome editing is an innovative and potential improvement for crustacean or fish aquaculture. Barman et al. (2017) applied this technology to establish specific gene function and to evaluate 
Table 2

Summary of recent studies on RNA-seq approach related with the improvement of penaeid shrimp commercial production (from 2017 to the present).

Category of trait for Organism Summary of findings $\quad$ Reference

improvement

Reproduction and sexual

differentiation

Penaeus monodon

Disease resistance/ immunology

Litopenaeus vannamei

Litopenaeus vanname

Litopenaeus vannamei

Fenneropenaeus chinensis

Marsupenaeus japonicus
Genomic improvement
Penaeus monodon enriched phagocytic hemocytes (using fluorescent magnetic beads) showed functional difference among this immune cell. Highly expressed transcript such as homologous to integrin-alpha $(M j-I n t g \alpha)$ was found and proposed as molecular marker candidate of phagocytic hemocytes.

Expression patterns (expressed sequences tags -ESTs) of ovary and eyestalk associated with regulation of gonadal maturation. Identification of candidate genes controlling this process, e.g.: vitellogenin receptor (vtgr), minichromosome maintenance $(\mathrm{mcm})$ family members and membrane progestin receptor gamma (mprg) steroid receptor. Transcriptome of ovaries and testes revealed transcripts related with important reproductive pathways, such as: gonadotropin-releasing hormone (GnRH) and progesterone-mediated oocyte maturation. These findings are helping to define strategies to minimize the $P$. monodon low capacity of reproduction in captivity. Through de novo transcriptome sequencing and assembly, 43 specific microRNAs (miRNAs) differentially expressed and 84 target genes that are involved in the ovarian development process were detected: catalytic and regulatory subunits of mitogenactivated protein kinase (MAPKK)25, extracellular signal-regulated kinase (ERK), fatty acid synthase (FAS), cyclin A, cyclin B30-34, and 14-3-3-like protein, among others. This information can be used to develop alternative technologies to eyestalk ablation.

Response of host immune system to acute hepatopancreas necrosis disease (AHPND) infection by comparative transcriptomic analyses. Major responsive expressed genes were detected in major metabolic processes such as carbohydrate, lipid and amino acid metabolism. Finally, genes implicated in cell growth and anti-apoptosis: src, iap2, cas2, cytochrome P450, gst and cytochrome $c$ oxidase were differentially expressed under Vibrio parahemolyticus infection (with Pir toxin proteins). lipopolysaccharide (LPS) show that several up-down regulated genes, such as Ubiquitin- proteasome pathway was activated (ubiquitin-conjugating enzyme E2C, $\mathrm{H} 1$ and H5b), and oxidative phosphorylation (cytochrome $c$ oxidase 1, NADH dehydrogenase 1 , Inosine- 5 '-monophosphate dehydrogenase $1 \mathrm{~b}$ and phospholipidtransporting ATPase IA) were downregulated.

Transcriptome by RNA-seq approach of farm animals with fast growth and high survival rates, challenged with White Spot Virus, directed to obtain genomic information for aquaculture development aiming higher growth gains and WSSVresistant shrimp. Gene annotation obtained for growth performance were related to myosin (MYSA), tropomyosin and myosin heavy chain, chitinase and molt-inhibiting hormone-like. On the other hand, frequent genes in the WSSV-exposed shrimp were related to crustacyanin 1 and 2 (CRA1 and CRA2), lectins and hemocyanin B and C (HCYB - HCYC) heavy chain.

The evaluation of molecular responses to white spot virus (WSV) oral infection by Illumina HiSeq ${ }^{\mathrm{TM}} 2500$ platform to analyze the transcriptome information for producing brooders with robust viral resistance. Function annotation of immune response pathways were phagosome, complement and coagulation cascades, proteasome, and antigen processing and presentation. Differentially expressed genes (DEGs) associated with growth were cathepsin L, myosin regulatory light chain 2 smooth muscle, and alpha-amylase. shrimp revealed annotated transcript most highly expressed of female gonad tissue: farnesoic acid $O$-methyltransferase (FAmET), phosphoenolpyruvate carboxykinase (PEPCK), glutathione peroxidase (GPx) and nasrat, linked to shrimp molt cycle and reproduction. In eyestalk, tissue was found hyperglycaemic hormone (CHH) mainly. Transcriptomic patterns discovered supply new genomic resources necessary to develop genetic improvement strategies in commercial hatcheries. Transcriptome analyses of hemocytes from shrimp immunologically stimulated with

Transcript expression profiles of different tissues types and larval stages of black tiger

\author{
Ventura-López et al., \\ 2017 \\ Uengwetwanit et al., \\ 2018
}

Zhao et al., 2018

Zheng et al., 2018.

Zhang et al., 2018a.

Santos et al., 2018b.

Shi et al., 2018.

Koiwai et al., 2018.

Huerlimann et al., 2018. knock-out of EcMIH in 12/250 (4.8\%) injected one-cell prawns, that exhibited changes in their phenotypes such as increased length and shorten metamorphosis time of larvae from mysis to postlarva stage. Also, CRISPRed animals did not experience health problems like early stage death or deformity, revealing the importance for future scientific research aiming at inducing molecular improvements for functional crustacean genomics and selective breeding.

\section{Conclusions}

The shrimp aquaculture industry is growing relaying mostly on the American species, L. vannamei. This dependency on just one species is not a healthy sign since diversification will offer better opportunities for adapting to changing conditions. Decapod crustaceans are a diverse group of organisms that shows vast physiological differences between 
species; therefore, species-specificity must be taken into account for developing biotechnological solutions.

Reproductive endocrinology of penaeid shrimps is not completely understood; the basic model of shrimp reproduction establishes a cascade and antagonistic hormonal control, based on three levels: central nervous system (CNS)/ x-organ-sinus gland level, androgenic gland (AG, males)/mandibular organ (MO) level, and male/female reproductive system and complementary target tissues (hepatopancreas, appendages) level. However, new reproduction factors have been discovered including red pigment concentrating hormone (RPCH), pigment-dispersing hormone (PDH), corazonin, glycoproteins, and Neuropeptide F.

Alternatives to eyestalk ablation is a major research frontier for the shrimp industry. Based on endocrinological advances, different molecules have been evaluated for inducing the predictable and reliable production of shrimp eggs without unilateral eyestalk ablation, including steroids, juvenoids, prostaglandins, neurotransmitters, and neurotransmitter antagonists. Serotonin and spiperone have given the most promising results for inducing ovarian maturation in the genus Litopenaeus; however, these therapies have not been further evaluated at commercial levels. Reproductive pheromones in crustaceans have only been related with mating behavior. In penaeid shrimps, there is only one report suggesting the existence of ovarian maturation inducing pheromones. Pheromone therapy is non-invasive, offering the industry a unique approach to controlled reproduction; therefore, this line of research should receive more attention. RNA interference (RNAi) using double-stranded RNA (dsRNA) molecules to silence GIH transcripts has been considered as an alternative technique to eyestalk ablation. The injection inhibited GIH transcript, but ovarian maturation and spawning rates have been inferior to eyestalk ablation or negligible. However, these studies have demonstrated the potential of the RNAi technology to silence GIH transcripts, and therefore, the underlying mechanisms of GIH synthesis must be further understood.

Improvements in product protection and commercial grow-out yields are important research frontiers. The induction of polyploidy in penaeid shrimps offers an alternative for implementing sterility, genetic protection, and growth rates. This technology could skew sex ratio towards females, which grow larger than males. Triploid induction at meiosis I or meiosis II has been developed, and the triploid larvae are viable to adult stages for $F$. chinensis, $M$. japonicus, and P. monodon; growth differences between triploid and diploid animals are not clearly defined, but sterility has been demonstrated.

The culture of hybrid shrimps is an alternative for improving yields in commercial operations. Inter-specific hybridization in penaeid shrimps has received some attention, but it is not advancing. The major problem to hybrid production seems to be fertilization and hatching of eggs; therefore, a new approach has been suggested for understanding and improving hybrid hatch rates. Shrimp female monosex culture offers an alternative to the traditional mixed sex cultures. The best approach for sex reversal technology was developed with $M$. rosenbergii, at commercial level, using gene silencing of IAG by RNAi for feminization of males or a single injection of AG cells for masculinization of females. AG ablation and implantation technologies have been evaluated in L. vannamei, without generating complete sex reversal of postlarvae starting at PL34. This species responds differently to AG ablation since males are capable of regenerating appendices, petasmas and appendices masculinae, in the absence of AGs, suggesting that sexual plasticity is different between Dendrobranchiata and Pleocyemata.

The reproduction of animals with culture genetic advantages has been facilitated by molecular markers associated with traits of commercial interest such as disease resistant, genetic diversity, population structure, kinship traceability, high-temperature tolerance, and growth. Microsatellites are particularly a powerful tool for hatchery stock management. Gene mapping for detecting quantitative trait loci linked to phenotypic commercial characteristics is based on SNP genotyping, RNA-Seq technology based on next-generation DNA sequencing platform, DNA microarrays, and RAD-seq. Transcriptome-mRNA sequencing facilitates the acquisition of gene expression data or the identification of novel transcripts for the aquaculture improvement of decapods models. Genomic edition by the use of the CRISPR technique in crustaceans is limited, but studies have demonstrated the importance of this technology for inducing molecular improvements for functional crustacean genomics and selective breeding.

Advances in larvae production include the development of commercial protocols for sperm, embryos and nauplii cryopreservation for genetic material preservation, and economical and efficient seedstock international trading. The use of larval stages for cryopreservation instead of embryos would have the advantage of higher tolerance to cryoprotectants and lower chances of failure embryonic development and/or hatching. In vitro fertilization for the shrimp farming industry is also important mainly for the improvement of breeding programs and larvae production. The application of this technique could improve our knowledge for the hybridization of penaeid shrimps, and combined with gametes cryopreservation, the number of broodstock to be kept in captivity could be reduced, representing lower costs for commercial hatching. The successful development of techniques for in vitro fertilization is most likely associated to the understanding of the spermatozoal capacitation and the control of egg activation.

Alternatives to eyestalk ablation for controlled ovarian maturation have been demonstrated in Litopenaeus based on neurotransmitter regulation; however, the environmental impact of this approach has to be evaluated. Maturation by RNAi requires further evaluation, and maturation pheromones have not been explored. Sex reversal, hybridization, in vitro fertilization, and seedstock cryopreservation of penaeid species require fundamental research. Triploid culture and genetic selection can be applied for some species for product protection; however, for L. vannamei, triploidization is not practical yet.

\section{Declarations of interest}

None.

\section{CRediT author statement}

Jorge Alfaro-Montoya participated in Conceptualization; Formal analysis; Visualization; Writing - original draft; Writing - review \& editing.

André Braga participated in Conceptualization; Formal analysis; Visualization; Writing - original draft; Writing - review \& editing. Rodolfo Umaña-Castro participated in Conceptualization; Formal analysis; Visualization; Writing - original draft; Writing - review \& editing.

\section{Acknowledgements}

We appreciate the valuable comments made by unknown referees. To Dr. Antonio Baeza and Jeff Sánchez for collaborating with the language editing.

\section{References}

Aflalo, E.D., Hoang, T.T.T., Nguyen, V.H., Lam, Q., Nguyen, D.M., Trinh, Q.S., Raviv, S., Sagi, A., 2006. A novel two-step procedure for mass production of all-male populations of the giant freshwater prawn Macrobrachium rosenbergii. Aquaculture 256 (1), $468-478$.

Aflalo, E.D., Dandu, R.V., Verghese, J.T., Rao, N., Samraj, T.Y., Ovadia, O., Sagi, A., 2014. Neo-females production and all-male progeny of a cross between two Indian strains of prawn (Macrobrachium rosenbergii): population structure and growth performance under different harvest strategies. Aquaculture 428, 7-15.

Akarasanon, K., Damrongphol, P., Poolsanguan, W., 2004. Long-term cryopreservation of spermatophore of the giant freshwater prawn, Macrobrachium rosenbergii (de Man). Aquac. Res. 35, 1415-1420.

Aktas, M., Gene, M.A., 2011. The effects of 17 ß-estradiol on growth, survival and feminization of green tiger shrimp, P. semisulcatus (Decapoda: Penaeidae). J. Anim. Vet Adv. 10 (5), 562-565. 
Alfaro, J., 1996. Effect of 17-alpha-methyltestosterone and 17-alpha-hydroxyprogesterone on the quality of white shrimp Penaeus vannamei spermatophores. J. World Aquac. Soc. 27 (4), 487-492.

Alfaro, J., Vega, L., 2010. Effects of transplants and extracts of thoracic nerve cordganglia on gonad maturation of penaeoid shrimp. Aquac. Res. 41, 182-188.

Alfaro, J., Lawrence, A.L., Lewis, D., 1993. Interaction of bacteria and male reproductive system blackening disease of captive Penaeus setiferus. Aquaculture 117, 1-8.

Alfaro, J., Komen, J., Huisman, E.A., 2001. Cooling, cryoprotectant and hypersaline sensitivity of penaeid shrimp embryos and nauplius larvae. Aquaculture 195, 353-366.

Alfaro, J., Muñoz, N., Vargas, M., Komen, J., 2003. Induction of sperm activation in open and closed thelycum penaeoid shrimps. Aquaculture 216, 371-381.

Alfaro, J., Zúñiga, G., Komen, J., 2004. Induction of ovarian maturation and spawning by combined treatment of serotonin and a dopamine antagonist, spiperone in Litopenaeus stylirostris and Litopenaeus vannamei. Aquaculture 236, 511-522.

Alfaro, J., Ulate, K., Vargas, M., 2007. Sperm maturation and capacitation in the open thelycum shrimp Litopenaeus (Crustacea: Decapoda: Penaeoidea). Aquaculture 270, 436-442.

Alfaro, J., Hernández, L., Zúñiga, G., Soto, R., Mejía-Arana, F., 2008a. Thoracic nerve cord - ganglia recognition in intraspecific and interspecific transplants in the white shrimp, Penaeus (Litopenaeus) vannamei. Aquaculture 288, 126-131.

Alfaro, J., Zúñiga, G., García, A., Rojas, E., 2008b. Preliminary evaluation of the effect of juvenile hormone III and methyl farnesoate on spermatophore quality of the white shrimp, Litopenaeus vannamei Boone, 1931 (Decapoda: Penaeidae). Rev. Biol. Mar Oceanogr. 43, 167-171.

Alfaro-Montoya, J., 2015. The effect of Ibuprofen on female and male reproduction of the open thelyca marine shrimp, Litopenaeus. Aquac. Res. 46, 105-116.

Alfaro-Montoya, J., Hernández, L., 2012. The histological structure of the androgeni gland and cellular cord of the male reproductive system of adult Litopenaeus and Rimapenaeus byrdi. J. Crust. Biol. 32, 351-357.

Alfaro-Montoya, J., Hernández-Noguera, L., Vega-Alpízar, L., Umaña-Castro, R., 2016. Effects of androgenic gland ablation on growth, sexual characters and spermatogenesis of the white shrimp, Litopenaeus vannamei (Decapoda: Penaeidae) males. Aquac. Res. 47 (9), 2768-2777.

Amano, M., Okumura, T., Okubo, K., Amiya, N., Takahashi, A., Oka, Y., 2009 Biochemical analysis and immunohistochemical examination of a GnRH-like immunoreactive peptide in the central nervous system of a decapod crustacean, the kuruma prawn (Marsupenaeus japonicus). Zool. Sci. 26, 840-845.

Aravin, A.A., Hannon, G.J., Brennecke, J., 2007. The piwi-piRNA pathway provides an adaptive defense in the transposon arms race. Science 318, 761-764.

Aungsuchawan, S., Browdy, C.L., Withyachumnarnkul, B., 2011. Sperm capacitation of the shrimp Litopenaeus vannamei. Aquac. Res. 42, 188-195.

Baghel, D.S., Lakra, W.S., Satyanarayana Rao, G.P., 2004. Altered sex ratio in giant fresh water prawn, Macrobrachium rosenbergii (de Man) using hormone bioencapsulated live Artemia feed. Aquac. Res. 35 (10), 943-947.

Barman, H.K., Rasal, K.D., Chakrapani, V., Ninawe, A.S., Vengayil, D.T., Asrafuzzaman, S., Jayasankar, P., 2017. Gene editing tools: state-of-the-art and the road ahead for the model and non-model fishes. Transgenic Res. 26 (5), 577-589.

Bart, A.N., Choosuk, S., Thakur, D.P., 2006. Spermatophore cryopreservation and artificial insemination of black tiger shrimp, Penaeus monodon (Fabricius). Aquac. Res. 37, 523-528.

Benzie, J.A.H., 1998. Penaeid genetics and biotechnology. Aquaculture 164, 23-47.

Benzie, J.A.H., Kenway, M., Ballment, E., 2001. Growth of Penaeus monodon $\times$ Penaeu esculentus tiger prawn hybrids relative to the parental species. Aquaculture 193, $227-237$.

Biao, X., Kaijin, Y., 2007. Shrimp farming in China: operating characteristics, environmental impact and perspectives. Ocean Coast. Manag. 50, 538-550.

Bin Bahar, M.H., 2016. Effect of Estrogen Hormone, 17ß-estradiol on Feminization, Survival and Growth of Banana Shrimp, Fenneropenaeus merguiensis (De Man, 1888) Postlarvae. M.Sc. Thesis. Institute of Tropical Aquaculture, University Malaysia Terengganu, Malaysia.

Bose, U., Kruangkum, T., Wang, T., Zhao, M., Ventura, T., Mitu, S.A., Hodson, M.P., Shaw, P.N., Sobhon, P., Cummins, S.F., 2017. Biomolecular changes that occur in the antennal gland of the giant freshwater prawn (Macrobrachium rosenbergii). PLoS One 12 (6), e0177064. https://doi.org/10.1371/journal.pone.0177064.

Brady, P., Elizur, A., Cummins, S.F., Ngyuen, N.H., Williams, R., Knibb, W., 2013. Differential expression microarrays reveal candidate genes potentially associated with reproductive dysfunction of captive-reared prawn Penaeus monodon. Aquaculture 400-401, 14-28.

Braga, A., Nakayama, C.L., Poerch, L., Wasielesky, W., 2013. Unistellate spermatozoa of decapods: comparative evaluation and evolution of the morphology. Zoomorphology $132,261-284$.

Braga, A., Suita de Castro, L.A., Poersch, L.H., Wasielesky, W., 2014. Spermatozoal capacitation of pink shrimp Farfantepenaeus paulensis. Aquaculture 430, 207-210.

Bray, W.A., Lawrence, A.L., 1992. Reproduction of Penaeus species in captivity. In: Fast, A., Lester, L.J. (Eds.), Marine Shrimp Culture: Principles and Practices. Elsevier Science Publishers B.V, The Netherlands, pp. 93-169.

Bray, W.A., Lawrence, A.L., Lester, L.J., 1990a. Reproduction of eyestalk-ablated Penaeus stylirostris fed various levels of total dietary lipids. J. World Aquac. Soc. 21, 41-52.

Bray, W.A., Lawrence, A.L., Lester, L.J., Smith, L.L., 1990b. Hybridization of Penaeus setiferus (Linnaeus, 1767) and Penaeus schmitti Burkenroad, 1936 (Decapoda). J. Crust. Biol. 10 (2), 278-283.

Burton, N.O., Burkhart, K.B., Kennedy, S., 2011. Nuclear RNAi Maintains Heritable Gene Silencing in Caenorhabditis elegans. Proceeding of the National Academy of Sciences of the United States of America. Vol. 108. pp. 19683-19688.

Castelo-Branco, T., Bambozzi, A., Mello, M.R.B., Oshiro, L.M.Y., 2014. Cryopreservation and sperm storage of the white shrimp. Bol. Inst. Pesca 40, 17-22.

Castelo-Branco, T., Batista, A.M., Guerra, M.M.P., Soares, R., Peixoto, S., 2015. Sperm vitrification in the white shrimp Litopenaeus vannamei. Aquaculture 436, 110-113.

Castelo-Branco, T., Quinto, B.P.T., Soares, R., Guerra, M.M.P., Peixoto, S., 2016. Cadaveric sperm viability in the white shrimp Litopenaeus vannamei. Aquac. Res. 47, 3350-3351.

Castelo-Branco, T., Guerra, M.M.P., Soares, R., Peixoto, S., 2018. Sperm vitrification of Litopenaeus vannamei: effect of cryoprotectant solutions on sperm viability and spawning quality after artificial insemination. Aquac. Int. 26, 913-920.

Chao, N.H., Liao, I.C., 2001. Cryopreservation of finfish and shellfish gametes and embryos. Aquaculture 197, 161-189.

Chapelle, S., 1986. Aspects of phospholipid metabolism in crustaceans as related to changes in environmental temperatures and salinities. Comp. Biochem. Physiol. 84B, 423-439.

Chen, T.I., Green, J.D., Clark, W.H., 1994. Sperm penetration of the vitelline envelope of Sicyonia ingentis eggs is mediated by a trypsin-like lysin of acrosomal vesicle origin. Develop. Growth Differ. 36, 259-273.

Chen, T., Zhang, L-P., Wong, N-K, Zhong, M., Ren, C-H., Hu, C-Q., 2014. Pacific white shrimp (Litopenaeus vannamei) vitellogenesis-inhibiting hormone (VIH) is predominantly expressed in the brain and negatively regulates hepatopancreatic vitellogenin (VTG) gene expression. Biol. Reprod. 90(3), 47, 1-10.

Chen, H.-Y., Kang, B.J., Sultana, Z., Wilder, M.N., 2018. Molecular cloning of red pig ment-concentrating hormone (RPCH) from eyestalks of the whiteleg shrimp (Litopenaeus vannamei): evaluation of the effects of the hormone on ovarian growth and the influence of serotonin (5-HT) on its expression. Aquaculture. https://doi.org/ 10.1016/j.aquaculture.2018.04.027.

Clark, W.H., Talbot, P., Neal, R.A., Mock, C.R., Salser, B.R., 1973. In vitro fertilization with non-motile spermatozoa of the brown shrimp Penaeus aztecus. Mar. Biol. 22, 353-354.

Clark, W.H., Kleve, M.C., Yudin, A.I., 1981. An acrosome reaction in natantian sperm. J. Exp. Zool. 218, 279-291.

Clark-Hachtel, C.M., Tomoyasu, Y., 2017. Two sets of wing homologs in the crustacean, Parhyale hawaiensis. bioRxiv. https://doi.org/10.1101/236281236281.

Coman, F.C., Sellars, M.J., Norris, B., Coman, G.J., Preston, N.P., 2008. The effects of triploidy on Penaeus (Marsupenaeus) japonicus (Bate) survival, growth and gender when compared to diploid siblings. Aquaculture 276, 50-59.

Dall, W., Hill, B.J., Rothlisberg, O.C., Staples, D.J., 1990. The biology of the Penaeidae. In: Blaxter, J.H.S., Southward, A.J. (Eds.), Advances in Marine Biology. Academic Press, UK (volume 27, 489 pp.)

Das, S., Shyamal, S., Durica, D.S., 2016. Analysis of annotation and differential expression methods used in RNA-Seq studies in crustacean systems. Integr. Comp. Biol. 56 (6), 1067-1079.

De Santis, C., Wade, N.M., Jerry, D.R., Preston, N.P., Glencross, B.D., Sellars, M.J., 2011. Growing backwards: an inverted role for the shrimp ortholog of vertebrate myostatin and GDF11. J. Exp. Biol. 214, 2671-2677.

Denli, A.M., Hannon, G.J., 2003. RNAi: an ever-growing puzzle. Trends Biochem. Sci. 28, 196-201.

Derby, C.D., Sorensen, P.W., 2008. Neural processing, perception, and behavioral responses to natural chemical stimuli by fish and crustaceans. J. Chem. Ecol. 34, 898-914.

Devanapally, S., Ravikumar, S., Jose, A.M., 2015. Double-stranded RNA made in C. elegans neurons can enter the germline and cause transgenerational gene silencing. Proc. Natl. Acad. Sci. U. S. A. 112, 2133-2138.

Diwan, A.D., 2005. Current progress in crustacean endocrinology-a review. Indian J. Exp. Biol. 43, 209-223.

Diwan, A.D., Kandasami, K., 1997. Freezing of viable embryos and larvae of marine shrimp, Penaeus semisulcatus de Hann. Aquac. Res. 28, 947-950.

Diwan, A.D., Harke, S.N., Panche, A., 2018. A review on genome mapping of penaeid shrimps of commercial importance. Aquac. Res. https://doi.org/10.1111/are.13751.

Dong, Q., Lin, J., Huang, C., 2004. Effects of cryoprotectant toxicity on the embryos and larvae of pacific white shrimp Litopenaeus vannamei. Aquaculture 242, 655-670.

Fairs, N.J., Quinlan, P.T., Goad, L.J., 1990. Changes in ovarian unconjugated and conjugated steroid titers during vitellogenesis in Penaeus monodon. Aquaculture 89, 83-99.

FAO, 2004. Manejo Sanitario y Mantenimiento de la bioseguridad de los laboratorios de postlarvas de camarón blanco (Penaeus vannamei) en América Latina. FAO Documento Técnico de Pesca. No. 450. Roma. (66 pp.).

FAO, 2018. The State of World Fisheries and Aquaculture 2018 - Meeting the Sustainable Development Goals. (Rome. 210 pp.).

Fazhan, H., Waiho, K., Ibrahim, W., Norfaizza, W., Megat, F.H., Ikhwanuddin, M., 2017 Inter-species mating among mud crab genus Scylla in captivity. Aquaculture 471, 49-54.

Feijó, R.G., Braga, A., Lanes, C.F.C., Figueiredo, M.A., Romano, L.A., Klosterhoff, M.C., Nery, L.E.M., Maggioni, R., Wasielesky, W., Marins, L.F., 2016. Silencing of gonadinhibiting hormone transcripts in Litopenaeus vannamei females by use of the RNA interference technology. Mar. Biotechnol. 18, 117-123.

Ferreira, A.V.L., Castro, E.J.T., Barbosa, M.A.S., Sousa, M.L.N.S., Paiva, M.A.N., Soares Filho, A.A., Sampaio, C.M.S., 2015. Toxicity of cryoprotectants agents in freshwater prawn embryos of Macrobrachium amazonicum. Zygote 26, 813-820.

Ferreira, A.V.L., Martins, M.F., Sousa, M.L.N.M., Soares Filho, A.A., Sampaio, C.M.S., 2017. Survival of Macrobrachium amazonicum embryos submitted to cooling. Zygote 25, 288-295.

Fingerman, M., 1997. Crustacean endocrinology: a retrospective, prospective, and introspective analysis. Physiol. Zool. 70, 257-269.

Fire, A., Albertson, D., Harrison, S.W., Moerman, D.G., 1991. Production of antisense RNA leads to effective and specific inhibition of gene expression in C. elegans muscle. 
Development 113, 503-514.

Fire, A., Xu, S., Montgomery, M.K., Kostas, S.A., Driver, S.E., Mello, C.C., 1998. Potent and specific genetic interference by double-stranded RNA in Caenorhabditis elegans. Nature 391, 806-811.

Fuller, B.J., 2004. Cryoprotectants: the essential antifreezes to protect life in the frozen state. CryoLetters 25, 375-388.

García-Machado, E., Pempera, M., Dennebouy, N., Oliva-Suarez, M., Mounolou, J.C., Monnerot, M., 1999. Mitochondrial genes collectively suggest the paraphyly of Crustacea with respect to Insecta. J. Mol. Evol. 49 (1), 142-149.

Gopal, C., Gopikrishna, G., Krishna, G., Jahageerdar, S.S., Rye, M., Hayes, B.J., Paulpandi, S., Kiran, R.P., Pillai, S.M., Ravichandran, P., Ponniah, A.G., Kumar, D., 2010. Weight and time of onset of female-superior sexual dimorphism in pond reared Penaeus monodon. Aquaculture 300, 237-239.

Griffin, F.J., Clark Jr., W.H., 1987. In vitro induction of the acrosome reaction in sperm of the penaeid shrimp Sicyonia ingentis. J. World Aquac. Soc. 18 (1), 32A.

Guan, Z.B., Shui, Y., Liao, X.R., Xu, Z.H., Zhou, X., 2014. Primary structure of a novel gonadotropin-releasing hormone $(\mathrm{GnRH})$ in the ovary of red swamp crayfish Procambarus clarkii. Aquaculture 418, 67-71.

Gui, T., Zhang, J., Song, F., Sun, Y., Xie, S., Yu, K., Xiang, J., 2016. CRISPR/Cas9mediated genome editing and mutagenesis of EcChi4 in Exopalaemon carinicauda. G3Genes Genom Genet, https://doi.org/10.1534/g3.116.034082.

Gunamalai, V., Kirubagaran, R., Subramoniam, T., 2006. Vertebrate steroids and the control of female reproduction in two decapod crustaceans, Emerita asiatica and Macrobrachium rosenbergii. Curr. Sci. 90, 119-123.

Guo, S., Kemphues, K.J., 1995. Par-1, a gene required for establishing polarity in C. elegans embryos, encodes a putative ser/thr kinase that is asymmetrically distributed. Cell 81, 611-620.

Gutiérrez-Millán, L.E., Peregrino-Uriarte, A.B., Sotelo-Mundo, R., Vargas-Albores, F., Yepiz-Plascencia, G., 2002. Sequence and conservation of a rRNA and tRNAVal mitochondrial gene fragment from Penaeus californiensis and comparison with Penaeus vannamei and Penaeus stylirostris. Mar. Biotechnol. 4 (4), 392-398.

Gwo, J.C., 2000. Cryopreservation of aquatic invertebrate semen: a review. Aquac. Res. 31, 259-271.

Gwo, J.C., Lin, C.H., 1998. Preliminary experiments on the cryopreservation of penaeid shrimp (Penaeus japonicus) embryos, nauplii and zoea. Theriogenology 49, 1289-1299.

Hagedorn, M., Hsu, E., Kleinhans, F.W., Wildt, D.E., 1997. New approaches for studying the permeability of fish embryos: towards successful cryopreservation. Cryobiology 34, 335-347.

Hannon, G.J., 2002. RNA interference. Nature 418, 244-251.

Hardege, J.D., Bartels-Hardege, H.D., Fletcher, N., Terschak, J.A., Harley, M., Smith, M.A., Davidson, L., Hayden, D., Müller, C.T., Lorch, M., Welham, K., Walther, T. Bublitz, R., 2011. Identification of a female sex pheromone in Carcinus maenas. Mar. Ecol. Prog. Ser. 436, 177-189.

Harlıoğlu, M.M., Farhadi, A., 2017. Feminization strategies in crustacean aquaculture. Aquacult. Int. https://doi.org/10.1007/s10499-017-0128-z.

Harlıoğlu, M.M., Yonar, M.E., Harlıoğlu, A.G., Yonar, S.M., Farhadi, A., 2017. Effects of different methods and times of $17 \beta$-estradiol treatment on the feminization success in the narrow-clawed crayfish Astacus leptodactylus (Eschscholtz, 1823). Invertebr. Reprod. Dev. https://doi.org/10.1080/07924259.2017.13403531-8.

Harrison, K.E., 1990. The role of nutrition in maturation, reproduction and embryonic development of decapod crustaceans: a review. J. Shellfish Res. 9, 1-28.

Hassan, M.M., Qin, J.G., Li, X., 2015. Sperm cryopreservation in oysters: A review of its current status and potentials for future application in aquaculture. Aquaculture 438, $24-32$.

Havird, J.C., Santos, S.R., 2016. Here we are, but where do we go? A systematic review of crustacean transcriptomic studies from 2014 to 2015. Integr. Comp. Biol. 56(6), $1055-1066$.

Homola, E., Landau, M., Laufer, H., 1989. The effects of biogenic amines on methyl farnesoate synthesis by disaggregated mandibular organ cells from the spider crab, Libinia emarginata. Am. Zool. 29, 61A.

Hooi, C.H., 1991. Effects of eyestalk ablation, thoracic ganglion extract and gonad extract from spent spawners on ovarian maturation in pond-reared shrimps, Penaeus monodon Fabricius. Aquacult. Fish. Manage. 22, 463-471.

Huberman, A., 2000. Shrimp endocrinology. A review. Aquaculture 191, 191-208.

Huerlimann, R., Wade, N.M., Gordon, L., Montenegro, J.D., Goodall, J., McWilliam, S. Sellars, M.J., 2018. De novo assembly, characterization, functional annotation and expression patterns of the black tiger shrimp (Penaeus monodon) transcriptome. Sci. Rep. 8. https://doi.org/10.1038/s41598-018-31148-4.

Hui, J.H., Tobe, S.S., Chan, S.M., 2008. Characterization of the putative farnesoic acid Omethyltransferase (LvFAMet) cDNA from white shrimp, Litopenaeus vannamei: Evidence for its role in molting. Peptides 29, 252-260.

Hulata, G., 2001. Genetic manipulations in aquaculture: a review of stock improvement by classical and modern technologies. Genetica 111, 155-173.

Ikhwanuddin, M., Noor-Hidayati, A.B., Aina-Lyana, N.M.A., Zulaikha, H., Muhd-Farouk, H., Abol-Munafi, A.B., 2015. In vitro Fertilization Technique in Banana Shrimp, Fenneropenaeus merguiensis (De Man, 1888). J. Fish. Aquat. Sci. 10 (6), 512-522.

Jenkins, T.L., Ellis, C.D., Stevens, J.R., 2018. SNP discovery in European lobster (Homarus gammarus) using RAD sequencing. Conserv. Genet. Resour. https://doi.org/10.1007/ s12686-018-1001-81-5.

Jones, D.B., Jerry, D.R., Khatkar, M.S., Raadsma, H.W., van der Steen, H., Prochaska, J., Zenger, K.R., 2017. A comparative integrated gene-based linkage and locus ordering by linkage disequilibrium map for the Pacific white shrimp, Litopenaeus vannamei. Sci. Rep. 7 (1), 10,360.

Kamio, M., Schmidt, M., Germann, M.W., Kubanek, J., Derby, C.D., 2014. The smell of molting: $N$-acetylglucosamino-1,5-lactone is a premoult biomarker and candidate component of the courtship pheromone in the urine of the blue crab, Callinectes sapidus. J. Exp. Biol. 217, 1286-1296.

Keller-Costa, T., Hubbard, P.C., Paetz, C., Nakamura, Y., Da Silva, J.P., Rato, A., Barata, E.N., Schneider, B., Canario, A.B.M., 2014. Identity of a tilapia pheromone released by dominant males that primes females for reproduction. Curr. Biol. 24, 2130-2135.

Kim, G., Yoon, T.H., Kang, H.E., Park, W.G., Kim, H.J., Choi, J.H., Kim, H.W., 2016. Complete mitochondrial genome of Kishi velvet shrimp, Metapenaeopsis dalei (Rathbun, 1902) (Crustacea: Decapoda: Penaeidae) in the East China Sea. Mitochond. DNA Part B 1 (1), 120-121.

Koiwai, K., Kondo, H., Hirono, I., 2018. RNA-seq identifies integrin alpha of kuruma shrimp Marsupenaeus japonicus as a candidate molecular marker for phagocytic hemocytes. Dev. Comp. Immunol. 81, 271-278.

Kruevaisayawan, H., Vanichviriyakit, R., Weerachatyanukul, W., Iamsaard, S., Withyachumnarnkul, B., Basak, A., Tanphaichitr, N., Sobhon, P., 2008. Induction of the acrosome reaction in black tiger shrimp, Penaeus monodon, requires sperm trypsin-like enzyme activity. Biol. Reprod. 79, 134-141.

Kuleshova, L.L., Shaw, J.M., Trounson, A.O., 2001. Studies on replacing most of the penetrating cryoprotectant by polymers for embryo cryopreservation. Cryobiology 43 , 21-31.

Kumagai, H., Nakanishi, T., Matsuura, T., Kato, Y., Watanabe, H., 2017. CRISPR/Casmediated knock-in via non-homologous end-joining in the crustacean Daphnia magna. PloS one 12 (10), e0186112.

Lawrence, A.L., Bray, W.A., Wilkenfeld, J.S., Lester, L.J., 1984. Successful interspecific cross of two species of marine shrimp Penaeus stylirostris and Penaeus setiferus in captivity. In: 15th Annu. Conf. of the World Aquaculture Society, 18-22 March 1984, Vancouver, B.C., Canada, p. 39. Abstr.

Leung-Trujillo, J.R., Lawrence, A., 1991. Spermatophore generation times in Penaeus setiferus, P. vannamei and P. stylirostris. J. World Aquacult. Soc. 22, 244-251.

Levy, T., Rosen, O., Eilam, B., Azulay, D., Aflalo, E.D., Manor, R., Sagi, A., 2016. A single injection of hypertrophied androgenic gland cells produces all-female aquaculture. Mar. Biotechnol. 18 (5), 554-563.

Lezcano, M., Granja, C., Salazar, M., 2004. The use of flow cytometry in the evaluation of cell viability of cryopreserved sperm of the marine shrimp (Litopenaeus vannamei). Cryobiology 48, 349-356.

Li, H.W., Ding, S.W., 2005. Antiviral silencing in animals. FEBS Letters 579, 5965-5973.

Li, F., Xiang, J., 1997. Preliminary studies on form, structure and function of androgenic gland in Penaeus chinensis. Chin. Sci. Bull. 42, 499-503.

Li, F., Xiang, J., Zhang, X., Zhou, L., Zhang, C., Wu, C., 2003. Gonad developmen characteristics and sex ratio in triploid Chinese shrimp (Fenneropenaeus chinensis). Mar. Biotechnol. 5, 528-535.

Li, S., Li, F., Sun, Z., Xiang, J., 2012. Two spliced variants of insulin-like androgenic gland hormone gene in the Chinese shrimp, Fenneropenaeus chinensis. Gen. Comp. Endocrinol. 177, 246-255.

Lin, M.-N., Ting, Y.-Y., Hanyu, I., 1988. Hybridization of two closed-thelycum penaeid species Penaeus monodon $\times P$. penicillatus and $P$. penicillatus $\times P$. monodon, by means of spermatophore transplantation. Bull. Taiwan Fish. Res. Inst. 45, 83-101.

Lin, C., Han, C.C., Tsai, S., 2013. Effect of thermal injury on embryos of banded coral shrimp (Stenopus hispidus) under hypothermal conditions. Cryobiology 66, 3-7.

Lindsay, L.L., Hertzler, P.L., Clark, W.H., 1992. Extracellular Mg + 2 induces an intracellular $\mathrm{Ca}+2$ wave during oocyte activation in the marine shrimp Sicyonia in gentis. Dev. Biol. 152, 94-102.

Liu, Z.J., Cordes, J.F., 2004. DNA marker technologies and their applications in aquaculture genetics. Aquaculture 238 (1-4), 1-37.

Liu, B., Wang, Q., Li, J., Liu, P., He, Y., 2010. A genetic linkage map of marine shrimp Penaeus (fenneropenaeus) chinensis based on AFLP, SSR, and RAPD markers. Chin. J. Oceanol. Limnol. 28 (4), 815-825.

Liu, Y., Xu, T., Robinson, N., Qin, J., Li, X., 2014. Cryopreservation of sperm in farmed Autralian greenlip abalone Haliotis laevigata. Cryobiology 68, 185-193.

Liu, Q.N., Chai, X.Y., Jiang, S.H., Zhou, C.L., Xuan, F.J., Zhang, D.Z., Tang, B.P., 2016. Identification of the complete mitochondrial genome of the pacific white shrimp Litopenaeus vannamei (Decapoda: Penaeidae). Mitochond. DNA Part A 27 (6), 4693-4695.

Lu, X., Luan, S., Hu, L.Y., Mao, Y., Tao, Y., Zhong, S.P., Kong, J., 2016. High-resolution genetic linkage mapping, high-temperature tolerance and growth-related quantitative trait locus (QTL) identification in Marsupenaeus japonicus. Mol. Genet. Genomics 291 (3), 1391-1405.

Lu, X., Luan, S., Kong, J., Hu, L., Mao, Y., Zhong, S., 2017. Genome-wide mining, characterization, and development of microsatellite markers in Marsupenaeus japonicus by genome survey sequencing. Chin. J. Oceanol. Limnol. 35 (1), 203-214.

Lu, X., Kong, J., Meng, X., Cao, B., Luo, K., Dai, P., Luan, S., 2018. Identification of SNP markers associated with tolerance to ammonia toxicity by selective genotyping from de novo assembled transcriptome in Litopenaeus vannamei. Fish Shellfish Immunol. 73, $158-166$.

Lugo, J.M., Morera, Y., Rodríguez, T., Huberman, A., Ramos, L., Estrada, M.P., 2006. Molecular cloning and characterization of the crustacean hyperglycemic hormone cDNA from Litopenaeus schmitti functional analysis by double-stranded RNA interference technique. FEBS J. 273, 5669-5677.

Lynn, J.W., Glas, P.S., Green, J.D., 1992. Assembly of the hatching envelope around the eggs of Trachypenaeus similis and Sicyonia ingentis in a low sodium environment. Biol. Bull. 183, 84-93.

Malati, E.F., Heidari, B., Zamani, M., 2013. The variations of vertebrate-type steroid hormones in the freshwater narrow-clawed crayfish Astacus leptodactylus (Eschscholtz, 1823) (Decapoda, Astacidae) during oocyte development. Crustaceana 86 (2), 129-138.

Mao, Z.C., Liu, P., Duan, Y.F., Li, J., Chen, P., Meng, X.L., 2016. Sequencing of complete mitochondrial genome of sword prawn Parapenaeopsis hardwickii (Miers)(Crustacea, 
Decapoda, Penaeidae). Mitochond. DNA Part B 1 (1), 259-260.

Maqsood, H.M., Ahmad, S.M., 2017. Advances in molecular markers and their applications in aquaculture and fisheries. GenAqua 1 (1), 27-41.

Mareddy, V.R., Rosen, O., Thaggard, H.B., Manor, R., Kuballa, A.V., Aflalo, E.D., Sagi, A., Paterson, B., Elizur, A., 2011. Isolation and characterization of the complete cDNA sequence encoding a putative insulin-like peptide from the androgenic gland of Penaeus monodon. Aquaculture 318, 364-370.

Matthew, B., Gopikrishna, G., Nicholas, A., Katneni, V.K., Mudagandur, S., Shekhar, J., Karthik, S., Jothivel, S., Gopal, C., Ravichandran, P., Matthew, K., Arnyasi, M., Ponniah, A.G., 2014. The development of a high density linkage map for black tiger shrimp (Penaeus monodon) based on cSNPs. PLoS ONE 9 (1), e85413. https://doi.org/ 10.1371/journal.pone.0085413.

Matzke, M.A., Matzke, A.J.M., 1995. How and why do plants inactivate homologous (Trans) gene? Plant Physiol. 107, 679-685.

Meister, G., Tuschl, T., 2004. Mechanisms of gene silencing by double-stranded RNA. Nature 431, 343-349.

Merlin, J.R., Mohanlal, D.L., Balasubramanian, C.P., Vijayan, K.K., Subramoniam, T., Tomy, S., Dayal, J.S., Gopal, C., 2016. Vertebrate-type steroid profile in different tissues of wild and endocrinologically manipulated female brood stocks of Penaeus monodon. Curr. Sci. 111 (7), 1194-1200.

Misamore, M., Browdy, C.L., 1997. Evaluating hybridization potential between Penaeus setiferus and Penaeus vannamei through natural mating, artificial insemination and in vitro fertilization. Aquaculture 150, 1-10.

Morales-Ueno, K., Montaldo, H.H., Ortega, A.M., Paniagua-Chávez, C.G., Castillo-Juárez, H., 2013. An extender solution for the short-term storage of Litopenaeus vannamei sperm to be used in artificial insemination. Aquac. Res. 44, 1254-1258.

Munang'andu, H.M., Evensen, Ø., 2017. Current advances in functional genomics in aquaculture. In: Marchi, F.A., Cirillo, P., Mateo, E.C. (Eds.), Applications of RNA-Seq and Omics Strategies-from Microorganisms to Human Health. IntechOpen, Rijeka, Croatia, pp. 173-212.

Nagaraju, G.P.C., 2007. Is methyl farnesoate a crustacean hormone? Aquaculture 272, 39-54.

Nagaraju, G.P.C., 2011. Reproductive regulators in decapod crustaceans: an overview. J. Exp. Biol. 214, 3-16.

Nagaraju, G.P.C., Ramamurthi, R., Reddy, P.S., 2002. Methyl farnesoate stimulates ovarian growth in Penaeus indicus. In: Harikumar, V.S. (Ed.), Recent Trends in Biotechnology, Agrobios, India. vol. 1. pp. 85-89.

Nair, S.R.S., 1987. In vitro fertilization of banana prawn Penaeus merguiensis De Man. Bull. Natl. Inst. Oceanogr. 20, 187-190.

Newton, S.S., Subramoniam, T., 1996. Cryoprotectant toxicity in penaeid prawn embryos. Cryobiology 33, 172-177.

Ngernsoungnern, A., Ngernsoungnern, P., Weerachatyanukul, W., Chavadej, J., Sobhon, P., Sretarugsa, P., 2008. The existence of gonadotropin-releasing hormone (GnRH) immunoreactivity in the ovary and the effects of GnRHs on the ovarian maturation in the black tiger shrimp, Penaeus monodon. Aquaculture 279, 197-203.

Ngernsoungnern, P., Ngernsoungnern, A., Sobhon, P., Sretarugsa, P., 2009. Gonadotropin-releasing hormone ( $\mathrm{GnRH})$ and a $\mathrm{GnRH}$ analog induce ovarian maturation in the giant freshwater prawn, Macrobrachium rosenbergii. Invert. Reprod. Dev. 53, 125-135.

Nguyen, D.V., Christiaens, O., Bossier, P., Smagghe, G., 2018a. RNA interference in shrimp and potential applications in aquaculture. Rev. Aquacult. 10, 573-584.

Nguyen, T.V., Jung, H., Rotllant, G., Hurwood, D., Mather, P., Ventura, T., 2018b. Guidelines for RNA-seq projects: applications and opportunities in non-model decapod crustacean species. Hydrobiologia. https://doi.org/10.1007/s10750-0183682-0.

Nicholas, A.R., Gopalapillay, G., Matthew, B., Vinaya Kumar, K., Mudagandur, S.S., Jayakani, S., Sarangapani, J., Gopal, C., Ravichandran, P., Thomas, G., Ponniah, A.G., 2014. QTL for white spot syndrome virus resistance and the sex-determining locus in the Indian black tiger shrimp (Penaeus monodon). BMC Genom. 15, 731.

Nimrat, S., Sangnawakij, T., Vuthiphandchai, V., 2005. Preservation of black tiger shrimp Penaeus monodon spermatophores by chilled storage. J. World Aquacult. Soc. 36, $76-86$.

Nimrat, S., Siriboonlamon, S., Zhang, S., Xu, Y., Vuthiphandchai, V., 2006. Chilled storage of white shrimp (Litopenaeus vannamei) spermatophores. Aquaculture 261, 944-951.

Ohs CL, D'Abramo LR, Petrie-Hanson, L., Kelly, A.M., 2006. Apparent control of sexua differentiation of freshwater prawn, Macrobrachium rosenbergii, through dietary administration of dopamine hydrochloride. J. Appl. Aquac. 18, 19-32.

Okamura, S., Kawaminami, T., Matsuura, H., Fusetani, N., Goshima, S., 2017. Behavioral assay and chemical characters of female sex pheromones in the hermit crab Pagurus filholi. J. Ethol. 35, 169-176.

Okumura, T., 2004. Perspectives on hormonal manipulation of shrimp reproduction. JARQ 38 (1), 49-54.

Otsu, T., 1960. Precocious development of the ovaries in the crab, Potamon dehaani, following implantation of the thoracic ganglion. Annot. Zool. Jpn. 33, 90-96.

Peregrino-Uriarte, A.B., Varela-Romero, A., Muhlia-Almazán, A., Anduro-Corona, I., Vega-Heredia, S., Gutiérrez-Millán, L.E., Yepiz-Plascencia, G., 2009. The complete mitochondrial genomes of the yellowleg shrimp Farfantepenaeus californiensis and the blue shrimp Litopenaeus stylirostris (Crustacea: Decapoda). Comp. Biochem. Physiol. Part D Genomics Proteomics 4 (1), 45-53.

Perez-Velazquez, M., González-Felix, M., Zúñiga-Panduro, M., Barraza-Guardado, R., 2010. Evidence of pre-zygotic barriers in attempts to cross-breed Penaeus (litopenaeus) vannamei (Boone) and P. (Litopenaeus) stylirostris (Stimpson) by means of artificial insemination. Aquaculture 304, 100-103.

Phetrungnapha, A., Kondo, H., Hirono, I., Panyim, S., Ongvarrasopone, C., 2015 Molecular cloning and characterization of Mj-mov-10, a putative RNA helicase involved in RNAi of kuruma shrimp. Fish Shellfish Immunol. 44, 241-247.
Pillai, M.C., Clark, W.H., 1987. Oocyte activation in the marine shrimp Sicyonia ingestis. J. Exp. Zool. 244, 325-329.

Pongtippatee, P., Vanichviriyakit, R., Chavadej, J., Plodpai, P., Pratoomchart, B., Sobhon, P., Withyachumnarnkul, B., 2007. Acrosome reaction in the sperm of the black tiger shrimp Penaeus monodon (Decapoda, Penaeidae). Aquac. Res. 38, 1635-1644.

Priyadarshi, H., Das, R., Pavan-Kumar, A., Gireesh-Babu, P., Javed, H., Kumar, S. Marappan, M., Somdutt Krishna, G., Chaudhari, A., 2017. Silencing and augmentation of IAG hormone transcripts in adult $M$. rosenbergii males affects morphotype transformation. J. Exp. Biol. 220, 4101-4108.

Quackenbush, L.S., 1986. Crustacean endocrinology; a review. Can. J. Fish. Aquat. Sci. 43, 2271-2282.

Ratcliff, F., Harrison, B., Baulcombe, D., 1997. A similarity between viral defense and gene silencing in plants. Science 276, 1558-1560.

Ravid, T., Tietz, A., Khayat, M., Boehm, E., Michelis, R., Lubzens, E., 1999. Lipid accumulation in the ovaries of a marine shrimp Penaeus semisulcatus (De Hann). J. Exp. Biol. 202, 1819-1829.

Raviv, S., Parnes, S., Segall, C., Davis, C., Sagi, A., 2006. Complete sequence of Litopenaeus vannamei (Crustacea: Decapoda) vitellogenin cDNA and its expression in en docrinologically induced sub-adult females. Gen. Comp. Endocrinol. 145, 39-50.

Ren, S., Mather, P.B., Tang, B., Hurwood, D.A., 2018. Levels of genetic diversity and inferred origins of Penaeus vannamei culture resources in China: Implications for the production of a broad synthetic base population for genetic improvement. Aquaculture 491, 221-231.

Riddle, N.C., Elgin, S.C.R., 2008. A role for RNAi in Heterochromatin formation in Drosophila. In: Paddison, P.J., Vogt, P.K. (Eds.), RNA Interference - Current Topics in Microbiology and Immunology. Springer-Verlag, Germany, pp. 185-209.

Robertson, S.M., Lawrence, A.L., Neil, W.H., Arnold, C.R., McCarty, G., 1988. Toxicity of the cryoprotectants glycerol, dimethyl sulfoxide, ethylene glycol, methanol, sucrose, and sea salt solutions to the embryo of red drum. Prog. Fish-Cult. 50, 148-154.

Rojas, E., Alfaro, A., 2007. In vitro manipulation of egg activation in the open thelycum shrimp Litopenaeus. Aquaculture 264, 469-474.

Rosen, O., Manor, R., Weil, S., Gafni, O., Linial, A., Aflalo, E.D., Ventura, T., Sagi, A., 2010. A sexual shift induced by silencing of a single insulin-like gene in crayfish: ovarian upregulation and testicular degeneration. PLoS One 5 (12), e15281.

Rotllant, G., Nguyen, T.V., Aizen, J., Suwansa-ard, S., Ventura, T., 2018. Toward the identification of female gonad-stimulating factors in crustaceans. Hydrobiologia. https://doi.org/10.1007/s10750-017-3497-4.

Sagi, A., Snir, E., Khalaila, I., 1997. Sexual differentiation in decapod crustaceans: role of the androgenic gland. Invertebr. Repr. Dev. 31 (1-3), 55-61.

Sagi, A., Manor, R., Ventura, T., 2013. Gene silencing in crustaceans: from basic research to biotechnologies. Genes 4 (4), 620-645.

Sancho-Blanco, C., Umaña-Castro, R., Alfaro-Montoya, J., 2018. Isolation and characterization of partial insulin-like androgenic gland hormone gene from distal terminal ampoules of three marine shrimp Penaeus species from the Eastern Pacific. Lat. Am. J. Aquat. Res. 46 (2), 461-468.

Santhoshi, S., Sugumar, V., Munuswamy, N., 2009. Serotonergic stimulation of ovarian maturation and hemolymph vitellogenin in the Indian white shrimp, Fenneropenaeus indicus. Aquaculture 291, 192-199.

Santos, C.A., Andrade, S., Freitas, P.D., 2018a. Identification of SNPs potentially related to immune responses and growth performance in Litopenaeus vannamei by RNA-seq analyses. PeerJ 6, e5154.

Santos, C.A., Andrade, S., Teixeira, A.K., Farias, F., Kurkjian, K., Guerrelhas, A.C., Freitas, P.D., 2018b. Litopenaeus vannamei transcriptome profile of populations evaluated for growth performance and exposed to white spot syndrome virus (WSSV). Front. Genet. 9, 120.

Saragusty, J., Arav, A., 2011. Current progress in oocyte and embryo cryopreservation by slow freezing and vitrification. Reproduction 141, 1-19.

Sarojini, R., Nagabhushanam, R., Fingerman, M., 1995. Mode of action of the neurotransmitter 5-hydroxytriptamine in stimulating ovarian maturation in the red swamp crayfish, Procambarus clarkii: an in vivo and in vitro study. J. Exp. Zool. 271, 395-400.

Scott, A.P., Sorensen, P.W., 1994. Time course of release of phenomenally active gonada steroids and their conjugates by ovulatory goldfish. Gen. Comp. Endocrinol. 96, 309-323.

Sellars, M.J., Li, F., Preston, N.P., Xiang, J., 2010. Penaeid shrimp polyploidy: global status and future direction. Aquaculture 310 (1), 1-7.

Sellars, M.J., Arce, S.M., Hertzler, P.L., 2012a. Triploidy induction in the Pacific white shrimp Litopenaeus vannamei: an assessment of induction agents and parameters, embryo viability, and early larval survival. Mar. Biotechnol. 14 (6), 740-751.

Sellars, M.J., Wood, A., Murphy, B., McCulloch, R.M., Preston, N.P., 2012b. Triploid black tiger shrimp (Penaeus monodon) performance from egg to harvest age. Aquaculture 324-325, 242-249.

Senarai, T., Saetan, J., Tamtin, M., Weerachatyanukul, W., Sobhon, P., Sretarugsa, P., 2016. Presence of gonadotropin-releasing hormone-like peptide in the central nervous system and reproductive organs of the male blue swimming crab, Portunus pelagicus, and its effect on spermatogenesis. Cell Tissue Res. 365, 265-277.

Shen, X., Ren, J., Cui, Z., Sha, Z., Wang, B., Xiang, J., Liu, B., 2007. The complete mitochondrial genomes of two common shrimps (Litopenaeus vannamei and Fenneropenaeus chinensis) and their phylogenomic considerations. Gene 403 (1), 98-109.

Shi, X., Meng, X., Kong, J., Luan, S., Luo, K., Cao, B., Cao, J., 2018. Transcriptome analysis of 'Huanghai No. 2' Fenneropenaeus chinensis response to WSSV using RNA-seq. Fish Shellfish Immunol. 75, 132-138.

Shockey, J.E., O'Leary, N.A., Vega, E., Browdy, C.L., Baatz, J.E., Gross, P.S., 2009. The role of crustins in Litopenaeus vannamei in response to infection with shrimp pathogens: An in vitro approach. Dev. Comp. Immunol. 33, 668-673.

Simon, C., Dumont, P., Cuende, F.X., Diter, A., AQUACOP, 1994. Determination of 
suitable freeing media for cryopreservation of Penaeus indicus embryos. Cryobiology $31,245-253$.

Song, N., Li, P., Zhang, X., Gao, T., 2018. Changing phylogeographic pattern of Fenneropenaeus chinensis in the Yellow Sea and Bohai Sea inferred from microsatellite DNA: implications for genetic management. Fish. Res. 200, 11-16.

Sun, Y., Zhang, J., Xiang, J., 2017. A CRISPR/Cas9-mediated mutation in chitinase changes immune response to bacteria in Exopalaemon carinicauda. Fish Shellfish Immunol. 71, 43-49.

Suquet, M., Dreanno, C., Fauvel, C., Cosson, J., Billard, R., 2000. Cryopreservation of sperm in marine fish. Aquacult. Res. 31, 231-243.

Suwansa-ard, S., Zhao, M., Thongbuakaew, T., Chansela, P., Ventura, T., Cummins, S.F., Sobhon, P., 2016. Gonadotropin-releasing hormone and adipokinetic hormone/corazonin-related peptide in the female prawn. Gen. Comp. Endocrinol. 236, 70-82.

Swetha, C.H., Girish, B.P., Reddy, P.S., 2016. Elucidation of the role of estradiol and progesterone in regulating reproduction in the edible crab, Oziothelphusa senex senex. RSC Adv. 6, 24,959-24,967.

Talbot, P., 1981. The ovary of the lobster Homarus americanus: structure of the mature follicle and origin of the chorion. J. Ultrastruct. Res. 76, 249-262.

Thongbuakaew, T., Siangcham, T., Suwansa-ard, S., Elizur, A., Cummins, S.F., Sobhon, P., Sretarugsa, P., 2016. Steroids and genes related to steroid biosynthesis in the female giant freshwater prawn, Macrobrachium rosenbergii. Steroids 107, 149-160.

Tiersch, T.R., Green, C.C. (Eds.), 2011. Cryopreservation in Aquatic Species, 2nd Edition. World Aquaculture Society. Baton Rouge, Louisiana, USA.

Tiersch, T.R., Yang, H., Jenkins, J.A., Dong, Q., 2007. Sperm cryopreservation in fish and shellfish. Spermatology 65, 493-508.

Tijsterman, M., Ketting, R.F., Okihara, K.L., Sijen, T., Plasterk, R.H., 2002. RNA helicase MUT-14-dependent gene silencing triggered in C. elegans by short antisense RNAs. Science 295, 694-697.

Timmons, L., Fire, A., 1998. Specific interference by ingested dsRNA. Nature 395, 854.

Timmons, L., Court, D.L., Fire, A., 2001. Ingestion of bacterially expressed dsRNA can produce specific and potent genetic interference in Caenorhabditis elegans. Gene 263, 103-112.

Tinikul, Y., Poljaroen, J., Nuurai, P., Anuracpreeda, P., Chotwiwatthanakun, C., Phoungpetchara, I., Kornthong, N., Poomtong, T., Hanna, P.J., Sobhon, P., 2011. Existence and distribution of gonadotropin-releasing hormone-like peptides in the central nervous system and ovary of the Pacific white shrimp, Litopenaeus vannamei. Cell Tissue Res. 343, 579-593.

Tinikul, Y., Poljaroen, J., Tinikul, R., Anuracpreeda, P., Chotwiwatthanakun, C., Senin, N., Poomtong, T., Hanna, P.J., Sobhon, P., 2014. Effects of gonadotropin-releasing hormones and dopamine on ovarian maturation in the Pacific white shrimp, Litopenaeus vannamei, and their presence in the ovary during ovarian development. Aquaculture 420-421, 79-88.

Tinikul, Y., Engsusophon, A., Kruangkum, T., Thongrod, S., Tinikul, R., Sobhonb, P., 2017. Neuropeptide F stimulates ovarian development and spawning in the female giant freshwater prawn, Macrobrachium rosenbergii, and its expression in the ovary during ovarian maturation cycle. Aquaculture 469, 128-136.

Tiu, S.H.K., He, J.G., Chan, S.M., 2007. The LvCHH-ITP gene of the shrimp (Litopenaeus vannamei) produces a widely expressed putative ion transport peptide (LvITP) for osmo-regulation. Gene 396, 226-235.

Tomy, S., Saikrithi, P., James, N., Balasubramanian, C.P., Panigrahi, A., Otta, S.K., Subramoniam, S., Ponniah, A.G., 2016. Serotonin induced changes in the expression of ovarian gene network in the Indian white shrimp, Penaeus indicus. Aquaculture 452, 239-246.

Treerattrakool, S., Panyim, S., Chan, S.M., Withyachumnarnkul, B., Udomkit, A., 2008. Molecular characterization of gonad-inhibiting hormone of Penaeus monodon and elucidation of its inhibitory role in vitellogenin expression by RNA interference. FEBS Journal 275, 970-980.

Treerattrakool, S., Panyim, S., Udomkit, A., 2011. Iduction of ovarian maturation and spawning in Penaeus monodon broodstock by double-stranded RNA. Mar. Biotechnol. 13, 163-169.

Treerattrakool, S., Chartthai, C., Phromma-in, N., Panyim, S., Udomkit, A., 2013. Silencing of gonad-inhibiting hormone gene expression in Penaeus monodon by feeding with GIH dsRNA-enriched Artemia. Aquaculture 404-405, 116-121.

Tsai, S., Lin, C., 2009. Effects of cryoprotectant on the embryos of banded coral shrimp (Stenopus hispidus); preliminary studies to establish freezing protocols. CryoLetters 30, 373-381.

Tsukimura, B., Kamemoto, F.I., 1991. In vitro stimulation of oocytes by presumptive mandibular organ secretions in the shrimp, Penaeus vannamei. Aquaculture 92, 59-66.

Tsutsui, N., Ohira, T., Kawazoe, I., Takahashi, A., Wilder, M.N., 2007. Purification of sinus gland peptides having vitellogenesis-inhibiting activity from the whiteleg shrimp Litopenaeus vannamei. Mar. Biotechnol. 9, 360-369.

Uengwetwanit, T., Ponza, P., Sangsrakru, D., Wichadakul, D., Ingsriswang, S. Leelatanawit, R., Karoonuthaisiri, N., 2018. Transcriptome-based discovery of pathways and genes related to reproduction of the black tiger shrimp (Penaeus monodon). Mar. Genomics 37, 69-73.

Ulate, K., Alfaro-Montoya, J., 2010. Sperm-egg incompatibility in inter-specific inseminations of Penaeus (litopenaeus) occidentalis, $P$. (Litopenaeus) stylirostris and $P$. (Litopenaeus) vannamei. Aquaculture 309, 290-292.

Vaca, A., Alfaro, J., 2000. Ovarian maturation and spawning in the white shrimp, Penaeus vannamei, by serotonin injection. Aquaculture 182, 373-385.

Valverde-Moya, J., Alfaro-Montoya, J., 2014. Productividad y rentabilidad del cultivo de camarones marinos en el Golfo de Nicoya, Costa Rica. REVMAR 6, 9-25.

Vázquez-Islas, G., Garza-Torres, R., Guerrero-Tortolero, D., Campos-Ramos, R., 2014. Histology of the androgenic gland and expression of the insulin-like androgenic gland hormone precursor gene in the genital organ of pacific white shrimp Litopenaeus vannamei. J. Crustac. Biol. 34, 293-299.

Vega-Alpízar, J.L., Alfaro-Montoya, J., Hernández-Noguera, L., Umaña-Castro, R., Aflalo, E.D., Sagi, A., 2017. Implant recognition and gender expression following ampouleandrogenic gland implantation in Litopenaeus vannamei females (Penaeidae). Aquaculture 468, 471-480.

Ventura, T., Sagi, A., 2012. The insulin-like androgenic gland hormone in crustaceans: from a single gene silencing to a wide array of sexual manipulation-based biotechnologies. Biotechnol. Adv. 30, 1543-1550.

Ventura, T., Manor, R., Aflalo, E.D., Weil, S., Raviv, S., Glazer, L., Sagi, A., 2009. Temporal silencing of an androgenic gland-specific insulin-like gene affecting phenotypical gender differences and spermatogenesis. Endocrinology 150, 1278-1286.

Ventura, T., Rosen, O., Sagi, A., 2011. From the discovery of the crustacean androgenic gland to the insulin-like hormone in six decades. Gen. Comp. Endocrinol. 173 (3), 381-388.

Ventura, T., Manor, R., Aflalo, E.D., Weil, S., Rosen, O., Sagi, A., 2012. Timing sexual differentiation: Full functional sex reversal achieved through silencing of a single insulin-like gene in the prawn, Macrobrachium rosenbergii. Biol. Reprod. 86, 90-96.

Ventura-López, C., Galindo-Torres, P.E., Arcos, F.G., Galindo-Sánchez, C., Racotta, I.S., Escobedo-Fregoso, C., Llera-Herrera, R., Ibarra, A.M., 2017. Transcriptomic information from Pacific white shrimp (Litopenaeus vannamei) ovary and eyestalk, and expression patterns for genes putatively involved in the reproductive process. Gen. Comp. Endocrinol. 246, 164-182.

Vuthiphandchai, V., Pengpun, B., Nimrat, S., 2005. Effects of cryoprotectant toxicity and temperature sensitivity on the embryos of black tiger shrimp (Penaeus monodon). Aquaculture 246, 275-284.

Vuthiphandchai, V., Nimrat, S., Kotcharat, S., Bart, A.N., 2007. Development of a cryopreservation protocol for long-term storage of black tiger shrimp (Penaeus monodon) spermatophores. Theriogenology 68, 1192-1199.

Wang, W., Tian, Y., Kong, J., Lib, X., Liu, X., Yang, C., 2012. Integration genetic linkage map construction and several potential QTLs mapping of chinese shrimp (Fenneropenaeus chinensis) based on three types of molecular markers. Russ. J. Genet. 48 (4), 422-434.

Wang, Q., Yu, Y., Yuan, J., Zhang, X., Huang, H., Li, F., Xiang, J., 2017. Effects of marker density and population structure on the genomic prediction accuracy for growth trait in Pacific white shrimp Litopenaeus vannamei. BMC Genetics 18 (1), 45.

Wikramanayake, A.H., Clark, W.H., 1994. Two extracellular matrices from oocytes of the marine shrimp Sicyonia ingentis that independently mediate only primary or secondary sperm binding. Dev. Growth Differ. 36 (1), 89-101.

Wikramanayake, A.H., Uhlinger, K.R., Griffin, F.J., Clark, W.H., 1992. Sperm of the shrimp Sicyonia ingentis undergo a bi-phasic capacitation accompanied by morphological changes. Dev. Growth Differ. 34 (3), 347-355.

Wilson, K., Cahill, V., Ballment, E., Benzie, J., 2000. The complete sequence of the mitochondrial genome of the crustacean Penaeus monodon: are malacostracan crustaceans more closely related to insects than to branchiopods? Mol. Biol. Evol. 17 (6), 863-874.

Wongprasert, K., Asuvapongpatana, S., Poltana, P., Tiensuwan, M., Withyachumnarnkul, B., 2006. Serotonin stimulates ovarian maturation and spawning in the black tiger shrimp Penaeus monodon. Aquaculture 261, 1447-1454.

Xiang, J., Li, F., Zhang, C., Zhang, X., Yu, K., Zhou, L., Wu, C., 2006. Evaluation of induced triploid shrimp Penaeus (fenneropenaeus) chinensis cultured under laboratory conditions. Aquaculture 259, 108-115.

Xu, W.-J., Morris, T.C., Samocha, T.M., 2018. Effects of two commercial feeds for semiintensive and hyper-intensive culture and four $\mathrm{C} / \mathrm{N}$ ratios on water quality and performance of Litopenaeus vannamei juveniles at high density in biofloc-based, zeroexchange outdoor tanks. Aquaculture 490, 194-202.

Yamauchi, M.M., Miya, M.U., Machida, R.J., Nishida, M., 2004. PCR-based approach for sequencing mitochondrial genomes of decapod crustaceans, with a practical example from kuruma prawn (Marsupenaeus japonicus). Mar. Biotechnol. 6 (5), 419-429.

Yano, I., 1985. Induced ovarian maturation and spawning in greasyback shrimp, Metapenaeus ensis, by progesterone. Aquaculture 47, 223-229.

Yano, I., 1987. Effect of 17a-hydroxy-progesterone on vitellogenin secretion in kuruma prawn, Penaeus japonicus. Aquaculture 61, 49-57.

Yano, I., Tsukimura, B., Sweeney, J.N., Wyban, J.A., 1988. Induced ovarian maturation of Penaeus vannamei by implantation of lobster ganglion. J. World Aquacult. Soc. 19, 204-209.

Yu, Y., Wei, J., Zhang, X., Liu, J., Liu, C., Li, F., Xiang, J., 2014. SNP discovery in the transcriptome of white Pacific shrimp Litopenaeus vannamei by next generation sequencing. PLoSONE 9 (1), e87218. https://doi.org/10.1371/journal.pone.0087218.

Yu, Y., Zhang, X., Yuan, J., Li, F., Chen, X., Zhao, Y., Huang, L., Zheng, H., Xiang, J., 2015 Genome survey and high-density genetic map construction provide genomic and genetic resources for the Pacific white shrimp Litopenaeus vannamei. Sci. Rep. 5, 15,612. https://doi.org/10.1038/srep15612.

Yu, Y., Liu, J., Li, F., Zhang, X., Zhang, C., Xiang, J., 2017a. Gene set based association analyses for the WSSV resistance of Pacific white shrimp Litopenaeus vannamei. Sci. Rep. 7, 40,549.

Yu, Y., Xiao, J.Z., Jianbo, Y., Quanchao, W., Shihao, L., Hao, H., Fuhua, L., 2017b. Identification of sex-determining loci in Pacific white shrimp Litopenaeus vannamei using linkage and association analysis. Mar. Biotechnol. 19 (3), 277-286.

Yuan, J., Zhang, X., Liu, C., Yu, Y., Wei, J., Li, F., Xiang, J., 2018. Genomic resources and comparative analyses of two economical penaeid shrimp species, Marsupenaeus japonicus and Penaeus monodon. Mar. Genomics 39, 22-25.

Zeeck, E., Harder, T., Beckmann, M., 1998. Uric acid: the sperm-release pheromone of the marine polychaete Platynereis dumerilii. J. Chem. Ecol. 24 (1), 13-22.

Zhang, T., Rawson, D., 1996. Feasibility studies on vitrification of intact zebrafish (Brachydanio rerio) embryos. Cryobiology 33, 1-13.

Zhang, D., Terschak, J.A., Harley, M.A., Lin, J., Hardege, J.D., 2011. Simultaneously 
hermaphroditic shrimp use lipophilic cuticular hydrocarbons as contact sex pheromones. PLoS ONE 6 (4), e17720.

Zhang, D., Gong, F., Liu, T., Guo, H., Zhang, N., Zhu, K., Jiang, S., 2015. Shotgun assembly of the mitochondrial genome from Fenneropenaeus penicillatus with phylogenetic consideration. Mar. Genomics 24, 379-386.

Zhang, D., Huang, J., Zhou, F., Gong, F., Jiang, S., 2016. The complete mitochondrial genome of banana shrimp Fenneropenaeus merguiensis with phylogenetic consideration. Mitochond. DNA Part A 27 (4), 2606-2607.

Zhang, Y., Gao, G., Lin, R., Aweya, J.J., Tao, M., Wang, F., 2018a. Transcriptome 2089 analyses reveal Litopenaeus vannamei hemocytes response to lipopolysaccharide. Fish Shellfish Immunol. 76, 187-195.

Zhang, J., Song, F., Sun, Y., Yu, K., Xiang, J., 2018b. CRISPR/Cas9-mediated deletion of $\mathrm{EcMIH}$ shortens metamorphosis time from mysis larva to postlarva of Exopalaemon carinicauda. Fish Shellfish Immunol. 77, 244-251.
Zhao, C., Fan, S., Qiu, L., 2018. Identification of microRNAs and their target genes associated with ovarian development in black tiger shrimp (Penaeus monodon) using high-throughput sequencing. Sci. Rep. 8 (1), 11,602.

Zheng, Z., Wang, F., Aweya, J.J., Li, R., Yao, D., Zhong, M., Zhang, Y., 2018. Comparative transcriptomic analysis of shrimp hemocytes in response to acute hepatopancreas necrosis disease (AHPND) causing Vibrio parahemolyticus infection. Fish Shellfish Immunol. 74, 10-18.

Zhi-Qiang, D., Ciobanu, D.C., Suneel, K.O., Rothschild, M.F., 2009. A gene-based SNP linkage map for Pacific white shrimp, Litopenaeus vannamei. Anim. Genet. 41 (3), 286-294.

Zhong, S., Zhao, Y., Wang, X., Song, Z., Zhang, Q., Chen, X., 2018. The complete mitochondrial genome of the cryptic species (Form II) in kuruma shrimp Marsupenaeus japonicus (Decapoda: Penaeidae). Mitochondr. DNA B 3 (1), 184-186. 